\title{
SIGNALING BY INSULIN RECEPTORS AND RELATED PROTEIN TYROSINE KINASES
}

\author{
D. Margriet Ouwens and J. Antonie Maassen \\ Department of Medical Biochemistry, Medical Faculty, State University Leiden, Leiden, The Netherlands
}

\begin{abstract}
SUMMARY
- The insulin receptor is a member of the largely expanding family of plasma membrane receptors. In general, ligand binding induces receptor dimerization leading to activation and tyrosine phosphorylation of the cytoplasmic catalytic domain of the receptor. Activation of receptor tyrosine kinases leads to several cellular responses like proliferation, differentitation and survival. The insulin receptor family distinghuishesfrom the other receptor tyrosine kinases in that it also mediates a metabolic response like stimulation of glucose uptake and glycogen synthesis. In this review the general principles of signaling by receptor tyrosine kinases are discussed. Besides, we point out the signaling pathways used by the insulin receptor itself.
\end{abstract}

\section{INTRODUCTION}

- Many cellular processes in eukaryotes such as proliferation, differentiation and apoptosis are regulated by external signals. An important group of external signals is represented by polypeptide growth factors. Some polypeptide growth factors bind with high affinity to a group of cell surface receptors with intrinsic tyrosine kinase (trk) activity, the receptor tyrosine kinases (Rtrk). Ligand binding to these receptors leads to activation of the Rtrk and of a whole array of early signaling intermediates, such as phospholipases, various serine/threonine kinases, small GTP-binding proteins, non-Rtrk, and protein tyrosine phosphatases. The activation of early signaling intermediates precedes the activation of several phosphorylation cascades, leading to stimulation of gene expression, changes in intracellular calcium levels, and the generation of phospholipid metabolites. Despite striking similarities in postreceptor signaling, Rtrk often exert their own specific effects. These pleiotropic responses can be partially explained by structural characteristics of the Rtrk, and tissue-specific expression of their ligands. Alternatively, the array of signaling intermediates activated by a specific Rtrk in a certain tissue may contribute to the nature of the response. In this review, the activation of early signaling pathways by Rtrk, and the occurrence of cross-talk between signaling pathways are discussed.

\section{STRUCTURAL AND FUNCTIONAL CHARACTERISTICS OF RECEPTOR TYROSIHE KIHASES}

\section{- Overall structure}

All Rtrk are transmembrane proteins $(1,2)$. The extracellular domain is the most distinctive feature in Rtrk. It contains a characteristic array of structural motifs, such as cysteine-rich stretches, and sequences homologous to immunoglobulin or fibronectin type III. The extracellular domain is involved in ligand binding and is often modified by $\mathrm{N}$-linked glycosylation and O-linked sugars. The single membrane spanning region is composed of a stretch of 20-25 generally hydrophobic amino acids, followed by several basic residues that represent the stop transfer signal anchoring the protein in the plasma membrane. The cytosolic domain contains a highly conserved trk catalytic domain. Carboxy- (C-) terminus to the catalytic domain resides a stretch with a length varying from a few residues up to 200 residues. The length and the primary structure of this C-terminal stretch varies among members of the Rtrk family. Based on sequence similarities and distinct structural characteristics, Rtrk have been classified in at least 15 subfamilies (Fig.l)(1-4) 

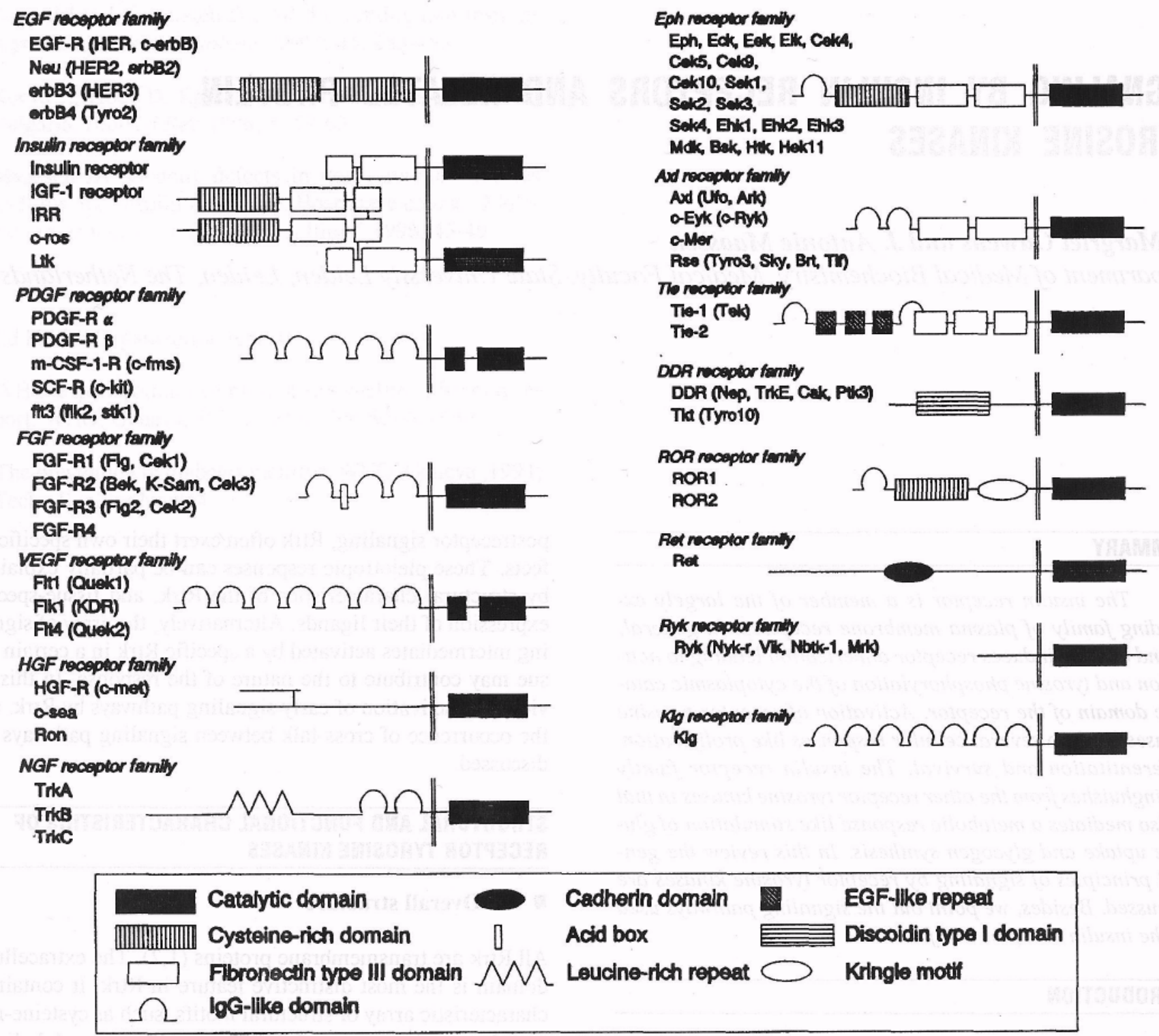

Figure 1, Structural topology of the subfamilies of receptor tyrosine kinases. Based on sequence similarities and distinct structural characteristics, receptor tyrosine kinases have been classified into 15 subfamilies $(1,4,25,26)$. The abbreviations are defined in the text.

\section{- $\quad$ Function and classification}

- $\quad$ Epidermal growth factor receptor family

The epidermal growth factor receptor (EGFR), also known as HER or c-ErbB, shares close sequence similarity with the transforming protein of avian erythroblastosis virus (v-ErbB) $(5,6)$. The EGFR is a monomeric Rtrk. The extracellular domain is
621 amino acids long and is characterised by the presence of two cysteine-rich clusters. In v-ErbB this domain is truncated, with only 65 amino acids at the external portion. The extracellular domain is separated from the cytoplasmic domain by a transmembrane region of 23 amino acids. The cytoplasmic domain contains an uninterrupted trk domain (Fig.l). Other members of the EGFR family include the p!85neu trk, also known as ErbB2, or HER2, ErbB3 (HERS), and ErbB4 (Tyro2) 
$(2,4)$. The EGFR is expressed on a variety of cell types, and activation of the receptor is implicated in cell proliferation and differentiation.

\section{- $\quad$ Insulin receptor family}

Members of the insulin receptor family are heterotetrameric proteins consisting of two oc-subunits that are disulfide-linked to two p-subunits (Fig. 1). The extracellular ligand binding domain contains one cysteine-rich cluster and three fibronectin type III repeats. The insulin receptor is derived from a precursor which is proteolytically cleaved to yield a mature receptor $(7,8)$. The CC-subunit is involved in ligand binding, whereas the transmembrane $\mathrm{p}$-subunit contains the cytoplasmic trk domain. Activation of the insulin receptor induces a pleiotropic response which can be divided into metabolic and growthpromoting effects (9). The stimulation of metabolic effects, that include glucose transport, glycogen synthesis and lipid synthesis, is a unique characteristics of the insulin receptor. Mutations in the insulin receptor and defects in the postreceptor signaling pathways are implicated in syndromes of insulin resistance and may contribute to the pathogenesis of non-insulin dependent diabetes mellitus (NIDDM) $(9,10)$. Other members of the insulin receptor family include the insulinlike growth factor-1 (IGF-1) receptor (11), the insulin receptor-related receptor (DRR), c-ros, and Ltk $(2,4)$. Activation of the IGF-1 receptor also induces a pleiotropic response (12). Targeted disruption of the IGF-1 receptor gene causes severe growth deficiency and the knock out mice die at birth (13).

\section{- $\quad$ Platelet-derived growth factor receptor family}

The platelet-derived growth factor receptors (PDGFR) are characterized by the presence of five immunoglobulin repeats in their extracellular domain and a cytoplasmic trk domain that is interrupted by a large sequence (-100 amino acids) termed the kinase insert region (Fig.. 1) (14). Activation of the PDGFR is implicated in the proliferation of mesenchymal cells. Other members of the PDGFR family include the macrophage-colony stimulating factor-1 (M-CSF-1, c-fins) receptor, the steel receptor (SCF receptor, $c$-kit), and the fms-like trk 3 (flt3), also known as fetal liver kinase 2 (flk2) or stem cell trk 1 (stkl) $(2,4)$.

\section{- Fibroblast growth factor receptor family}

The extracellular domain of the fibroblast growth factor receptor (FGFR) family is composed of three immunoglobulin-like repeats. In addition, the extracellular domain harbours an acid box, consisting of eight acidic amino acids, which is located between the first and the second immunoglobulin domain (Fig. 1). The catalytic trk domain is interrupted by a small (14 amino acids) kinase insert sequence. The prototype for the
FGFR family, FGFR1, was originally identified as a Fms-like gene (Fig) (15). Subsequently, a receptor for basic FGF that was purified from chicken embryo, chicken embryo kinase 1 (Cekl), was found to be the chicken Fig product $(2,4,15)$. Homologsfor Fig have been isolated from a variety of species, including human, mouse, and chicken $(2,4,15)$. Other members of the FGFR family include FGFR2, also known as bacterial expressed kinase (Bek), KATO-III cell-derived stomach cancer amplified gene (K-sam), Cek3, or TK14 $(2,4)$, FGFR3, also known as Flg2 and Cek2(2,4), andFGFR4 $(2,4)$. Mutations in the FGFR1, FGFR2, and FGFR3 genes are associated with autosomal dominant skeletal disorders, such as Jackson-Weiss syndrome, Crouzon syndrome, PfeifTer syndrome, achondroplasia. hypochondroplasia, and thantophoric dysplasia. However, transgenic mice expressing a dominant negative form of the FGFR1 show a disrupted organization of keratinocytes, indicating a role for FGFR1 in keratinocyte differentiation.

\section{- $\quad$ Vascular endothelial growth factor receptor family}

The vascular endothelial growth factor receptor (VEGFR) family is highly related to the PDGFR family. The VEGFR family differs from the PDGFR family in that the extracellular domain is composed of seven immunoglobulin repeats (Fig. 1). The catalytic trk domain is interrupted by a large kinase insert region in a similar way as in the PDGFR family. The first member of the VEGFR family that was isolated is Flt-1 (fms-like trk), also known as Quek-1, embryonic receptor kinase 2 (EmRK2) $(2,4)$. Other members of the VEGFR family include fetal liver kinase-1 (Flk-1), also known as KDR $(2,4)$, and Fit4, also known as Quek-2 $(2,4)$. The VEGFR are exclusively expressed in endothelial cells $(2,4)$. Targeted disruption of the Flt1 gene suggests an essential role for this protein in the organization of embryonic vasculature, but not for endothelial cell differentiation (16). The Flk-1 gene is essential for yolk-sac blood island formation and embryonic angiogenesis (17).

\section{- Hepatocyte growth factor receptor family}

The hepatocyte growth factor receptor (HGFR) family are heterodimeric proteins that are formed by proteolytic cleavage of a precursor. The mature receptor consists of an entirely extracellular oc-subunit that is disulfide-linked to the membrane spanning P-subunit (Fig.l) $(2,4)$. The P-subunit contains an uninterrupted trk catalytic domain. Members of the HGFR family include the HGFR, also known as the c-met proto-oncogene, the proto-oncogene $c$-sea, and the Ron trk $(2,4)$. Activation of the HGFR is implicated in the mitogenic response of epithelial cells.

\section{Nerve growth factor receptor family}

The prototype for the nerve growth factor receptor (NGFR) is 
trkA receptor. It is encoded by the cellular counterpart of trk oncogene that has originally been identified as a rearranged human oncogene (18 and Refs therein). The extracellular domain of the NGFR family shows some homology with immunoglobulin and fibronectin type III domains. In addition a leucine-rich repeat is found at the amino terminal part (Fig. 1). Other members of the NGFR family include trkB and trkC $(2,4,18)$. trkB and trkC are both expressed as full length proteins and as C-terminal truncated receptors which have complete extracellular and transmembrane domains, but lack the cytoplasmic catalytic domain. Activation of the trk proteins is implicated in the growth, differentiation and survival of neurons (18). Mice with targeted disruption of trkA or trkC genes survive for a few weeks but have severe defects in the sympathetic nervous system and in muscle afferents, respectively. Mice lacking trkB gene die shortly after birth, apparently because they are unable to feed. In these mice, neurons in the facial, trigeminal, and dorsal root ganglia, which normally express trkB, are not developed (2).

\section{- Erythropoietin-producing hepatic cell line receptor family}

The erythropoietin-producing hepatic cell line-like (Eph-like) proteins resemble the largest class of Rtrk. The prototype for this family is Eph proteins $(2,4)$. The extracellular domain of the Eph-like proteins are composed of a cysteine-rich domain, and two fibronectin type III domains. The cytosolic trk domain is uninterrupted (Fig.l). Most members of the Eph receptor family, such as Elk (Eph-like kinase), also known as chickenembryo kinase 6 (Cek6), Eek (Eph- and Elk-related kinase), Cek4, also known as mouse-embryo kinase 4 (Mek4), and human-embryo kinase (Hek), Cek5 (Hek5, Nuk), Sekl (Cek8, Hek8), Sek2, Sek3, Sek4, Eph-homologous kinase (Ehkl, Cek7, Hek7), Ehk2, Ehk3, mouse developmental kinase (Mdk) and brain-specific kinase (Bsk), are almost exclusively expressed in the developing nervous system where they are implicated in axonal guidance $(2,4)$. Eph, epithelial cell kinase (Eck), and hepatoma transmembrane kinase (Htk) show a broader tissue expression. Other Eph family members include Cek9, CeklO (Hek2) and Hekll $(2,4)$.

\section{- Axl receptor family}

The Axl subfamily of Rtrk possess extracellular domains that are composed of two ammo-terminal immunoglobulin-like domains and two fibronectin type III domains (Fig. 1). This combination is often observed in neural cell adhesion molecules and receptor protein tyrosine phosphatases, and suggests an involvement of the Axl Rtrk in cell adhesion processes.The Axl receptor family contains distinct sequences in the trk domain. The prototype of the Axl family, Axl, also known as Ufo, Ark, was originally identified as a transform- ing gene from the DNA of patients with chronic myelogenic leukemia (2). Overexpression of Axl in NIH3T3 cells causes neoplastic transformation with the concomitant appearance of a $140 \mathrm{kD}$ Axl tyrosine phosphorylated protein. Other members of the Axl family include c-Eyk, also known as c-Ryk. Rse, also known as Tyro3, Sky, Bit, or Tif, and c-Mer (2). Rse is expressed at high levels in the adult brain, suggesting that Rse may function as a novel neurotrophic receptor. c-Mer is almost exclusively expressed in monocytic lineages.

\section{- $\quad$ Tie receptor family}

Members of the Tie receptor family are characterized by an exceptional multidomain structure of the extracellular domain, consisting of a cluster of three EGF homology motifs embedded between two immunoglobulin-like loops, which are followed by three fibronectin type III domains (Fig. 1). Members of the Tie family include Tie-1, also known as Tek, and Tie-2 (2). Tie-1 and Tie-2 are specifically expressed in vascular endothelial cells during normal development and pathological conditions such as tumor angiogenesis. The structure of the extracellular domain suggests an involvement of the Tie-proteins in cell-cell adhesion in the vascular endothelium. Mice with a targeted disruption of the Tie-1 gene die immediately after birth as a result of breathing difficulties. Tie- $1 \sim$ embryos fail to establish integrity of vascular endothelial cells, resulting in oedema and localized haemorrhage (19). Mice with a targeted disruption of the Tie-2 gene die at embryonic day 10.5 as a result of malformations in the vascular network (19).

\section{- $\quad$ Discoidin domain receptor family}

The discoidin domain receptor (DDR) was originally identified as a breast carcinoma phosphoprotein (2). The extracellular domain of DDR, also known as Nep, trkE, Cak, or Ptk-3, has homology to Dictyostelium dicoideum lectin dicoidin-I, and contains hydrophilic proline/glycine-rich sequences (Fig.l). Discoidin-I domains show homology with putative phospholipid-binding domains found in other cell adhesion molecules such as the coagulation factors V and VIII and the neuronal recognition protein A5. Discoidin type I domains are also found in Tyro 10, also known as Tkt (2). The catalytic domain of TyrolO exhibits significant similarity to the trk family of neurotrophin receptors.

\section{- $\quad$ Ror receptor family}

Members of the Ror family (Rorl andRor2) of Rtrk were identified by a polymerase chain reaction-based screen for new members of the trk family. Structural differences in the extracellular domain, which contains a cysteine-rich domain, an immunoglobulin-like domain, and a kringle motif (Fig.l), place the Ror proteins in a separate class of Rtrk (2). The D. 
melanogaster homolog of Ror proteins (D-Ror) shows an even greater similarity with the catalytic domain of the trk proteins when compared to the human Ror proteins. Based on its neural-specific expression pattern, it is suggested that D-Ror may encode a neurotrophic receptor that functions during early stages of neural development.

\section{- $\quad$ Ret receptor family}

The Ret proto-oncogene encodes a Rtrk, in which the extracellular domain contains a sequence homologous to cadherin, a cell adhesion molecule (Fig.l). Germline mutations in the Ret gene are responsible for three different inherited cancer syndromes namely multiple endocrine neoplasia type $2 \mathrm{~A}$ and type $2 \mathrm{~B}$, and familial medullary thyroid carcinoma as well as for Hirschsprung disease (2). Mice with a targeted disruption of Ret gene die shortly after birth. The knock-out mice lack kidneys and enteric neurons pointing to a requirement for Ret in organogenesis and neurogenesis (20).

\section{- $\quad$ Ryk receptor family}

The Ryk Rtrk, also known as Nyk-r, Vik, Nbtk-1, or Mrk, (2) has a relatively short (-200 amino acids) extracellular domain (Fig.l) and some unusual substitutions at highly conserved residues in their catalytic domain. These substititions were also found in the D. melanogaster counterpart of Ryk, Drosophila derailed (Drl) (2). In mice, Ryk is predominantly expressed during hematopoietic development (2). Genetic studies in D. melanogaster suggest an involvement for $\mathrm{Drl}$ in neuronal pathway recognition (2).

\section{- $\quad$ Kinase-like gene receptor family}

The kinase-like gene $(\mathrm{Klg})$ protein is a transmembrane protein (2). The extracellular domain contains seven immunoglobulin-like sequences and is homologous to the VEGFR family (Fig. 1). As the catalytic domain lacks the highly conserved DFG motif, it is uncertain whether the Klg protein has intrinsic trk activity

\section{- Catalytic activity}

\section{- $\quad$ Ligand-induced dimerization}

Except for the insulin receptor family all Rtrk undergo a transition from a monomeric to a dimeric state upon ligand binding. This dimerization is inititiated through a ligand-induced conformational change of the extracellular domain that stabilizes interactions between adjacent cytoplasmic domains and leads to activation of the catalytic domain by molecular interaction $(1,21,22)$. In the case of the insulin receptor family, that preexists as a dimer of oc-p pairs, ligand binding presum- ably causes conformational changes in the preformed dimeric receptor that comprise an allosteric transition to yield an active dimer (Fig.2A) (1).

Receptor dimerization can take place between two identical receptor molecules (homodimerization); between different members of the same receptor family (heterodimerization); or between a receptor and an accessory, coreceptor protein (heterodimerization). Ligand binding induces homo- or heterodimerization via two possible mechanisms. It may be mediated by simultaneous binding of a dimeric ligand to two receptor molecules. Examples of dimeric ligands, which thus contain two identical receptor-binding epitopes, include PDGF, CSF-1 and stem cell factor (SCF) (21). In addition to bridging the ligand between both receptors, direct interactions between the receptors involving epitopes located outside the ligandbinding domains may be important for stabilization of the receptor dimer.

A number of other growth factors such as EGF and FGF are monomeric in solution. A monomeric ligand binding can induce conformational changes in the receptor that stabilize its active dimeric form. However, evidence is emerging that both EGF and FGF bind to their cognate receptors in a multivalent manner. In the case of EGF, calorimetric studies indicate that a single EGF molecule can bind simultaneously to two receptor molecules (21). In the case of FGF, plasma membrane heparan sulfate proteoglycans act as coreceptor molecules that bind multiple FGF (23). In this way, FGFR dimerization is induced by multivalent binding of the FGF-heparan complex (Fig.2B) (23).

Ligands for the Eph receptor family are all membrane anchored proteins via either glycosylphosphatidylinositol or transmembrane domain (24). These ligands, which are inactive in soluble form, probably facilitate receptor dimerization by their membrane attachment.

\section{- Homodimerization and heterodimerization}

The occurrence of ligand-induced homo- or heterodimerization provides possible means for increasing the diversity in signaling. In the case of PDGFR family, the two related PDGFR, PDGFRa and PDGFR(5, bind three types of dimeric PDGF ligands. The dimeric PDGF ligands are composed of disulphide linked A- or B-chains in either homodimeric (AA or $\mathrm{BB}$ ) or heterodimeric $(\mathrm{AB})$ combinations. The A-chain of PDGF binds only to a-receptors, while the $\mathrm{B}$ chain binds both a- and $\mathrm{p}$ receptors with high affinity $(21,22)$. In line with this, PDGF AA induces aa-receptor homodimers only, PDGF AB induces aa-receptor homodimers and ap-receptor heterodimers, whereas PDGF BB induces all three combinations of receptors $(21,22)$. It has been observed that each receptor dimer 
A

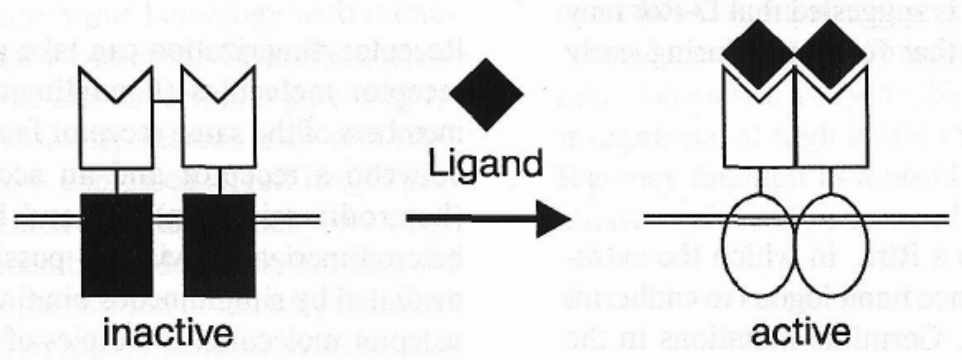

B

heparan sulfate proteoglycan

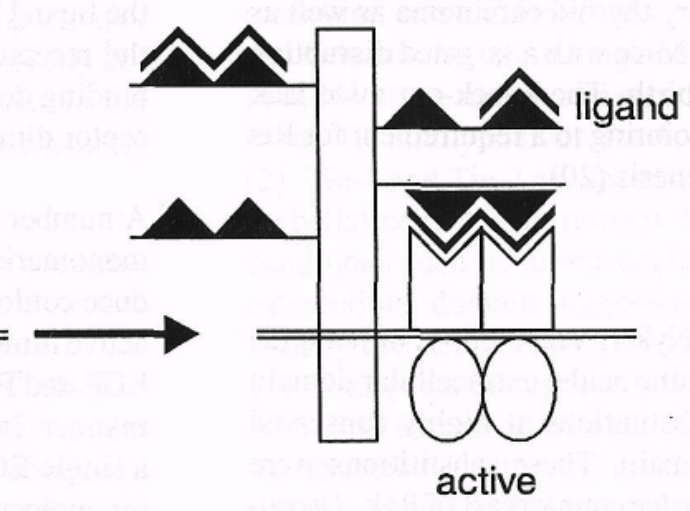

C

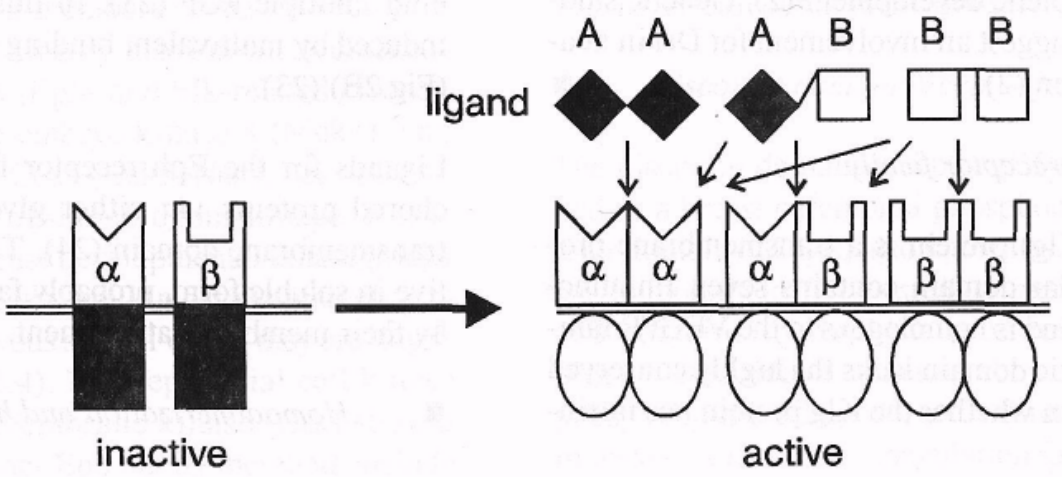

Figure 2. Models of receptor subclass-specific variations of the mechanism of activation by dimerization. (A) Allosteric activation of disulfide-stabilized receptor dimers. In the insulin receptor family, ligand binding results in conformational changes in the receptor that comprise an allosteric transition to yield an active dimer. (B) Receptor dimerization involving an accessory molecule. In the FGF receptor family, heparan sulfate proteoglycans in the plasma membrane act as accessory molecules that bind multiple FGF molecules. In this -way, FGF receptor dimerization and activation is induced by multivalent binding of the FGF-heparan sulfate proteoglycan complex. (C) Homo- and heterodimerization in the PDGF receptor family. The two related PDGF receptors, PDGFRa and PDGFRfi bind three types of dimeric PDGF ligands. The A-chain of PDGF binds only to a-receptors, -while the B-chain binds both a- and ${ }^{\wedge}$-receptors with high affinity. The repertoire of ligand specificity is increased through heterodimerization. As the cytoplasmic domains of the PDGFRaand PDGFRfi contain distinct autophosphorylation sites, specific signals are generated from each receptor dimer formed. 
elicits specific signals with respect to the stimulation of chemotaxis, actin reorganization and mitogenesis (2). Thus, the cell response to PDGF depends on the isoform of PDGF and the type of PDGFR expressed on the target cell (Fig.2C).

Heterodimerization is also observed between members of the EGFR family, EGFR, ErbB2, ErbB3, and ErbB4. Ligands for this receptor family include EOF, transforming growth factor-a, amphiregulin, heparin-binding EGF, betacellulin, and neu differentiation factor (NDF), also known as heregulin (21). So far, it has been reported that EGF binding induces homodimerization of the EGFR (21), and heterodimerization between EGFR/ErbB2, and EGFR/ErbBJ $(1,21,22)$. NDF binding leads to the formation of ErbB3 and ErbB4 homodimers, or ErbB2/ ErbB3 and ErbB2/ErbB4 heterodimers $(21,22)$. In analogy to the PDGFR, the formation of homo- or heterodimers in response to ligands for the EGFR family results in the activation of specific signaling pathways leading to different cellular responses. It is interesting to note that ErbB3 lacks certain highly conserved amino acids in the catalytic domain (2), and has no kinase activity. This suggests that ErbB3 acts as a substrate for EGFR and ErbB2 in the heterodimer.

Heterodimeriztion within an existing dimer has been noted between the insulin receptor and the insulin-like growth factor-1 receptor (1).

\section{- $\quad$ The tyrosine kinase domain}

The trk domain catalyzes the transfer of the y phosphate of a magnesium-adenosine triphosphate complex (Mg-ATP) to a protein substrate. The catalytic domains of serine/threonine kinases and trk are composed of-250-300 amino acids. Within the catalytic domain of distinct trk, sequence identities range from 32 to $95 \%$. Many conserved residues in the catalytic domain of trk are also conserved in the family of serine/threonine kinases $(3,25,26)$.

A 306-residue stretch of the insulin receptor containing the entire catalytic domain has been crystallized (27). The overall structure is similar to the structures obtained from the catalytic domain of the serine/threonine kinases cAMP-dependent protein kinase (PKA) (28), cyclin-dependent kinase 2, extracellular regulated kinase 2, and twitchin kinase. The catalytic domain is composed of two lobes that form a cleft in which Mg-ATP binds. It is assumed that within this cleft the protein substrate and $\mathrm{Mg}$-ATP are brought in close vicinity to each other. The small amino-terminal lobe contains the highly conserved GlyXGlyXXGlyX(21)Lys ${ }^{1030}$ motif and a Glu ${ }^{1047}$ residue which are conserved in all protein kinases. The function of the glycine loop is to anchor the phosphate moiety and, in particular, to help position the y phosphate so that it is poised for transfer. In the structure of PKA, the side chains of Lys ${ }^{72}$
(Lys1030 in the insmin receptor) and Glu91 (Glu1047) together with the side chain of Asp184 (Asp1150) in the Cterminal lobe form a triad close to the yphosphate of Mg-ATP. Lys72 (Lys1030) is required for ATP-binding by interacting with the a and p phosphates, while Glu91 (Glu1047) and Asp184 (Asp1150) function inthechelation of Mg2+.

The amino-terminal lobe is connected by a single strand to the large C-terminal lobe containing the principal elements of the active site such as the catalytic loop, the activation loop and the peptide-binding site. The relative orientation of the amino- and C-terminal lobe differs between the insulin receptor and PKA. When compared to PKA, the two lobes in the inactive insulin Rtrk domain are rotated away from each other. This orientation holds Lys ${ }^{1030}$, a residue in the amino-terminal lobe implicated in ATP-binding, at a comparatively large distance from the catalytic residues in the $\mathrm{C}$-terminal lobe.

The catalytic loop in the C-terminal lobe is formed by the highly conserved HRDLAARN (residue 1130-1137) stretch. In the catalytic loop $\operatorname{Asp}^{1132}$ (Asp ${ }^{166}$ in PKA) and $\operatorname{Asn}^{1137}\left(\mathrm{Asn}^{171}\right)$ are nearly invariant in both the serine/threonine kinase and trk families. Asp ${ }^{1132}$ is the catalytic base in the phosphotransfer reaction. In the structure of PKA, the side chains of $\mathrm{Asn}^{171}$ $\left(\mathrm{Asn}^{1137}\right), \operatorname{Asp}^{166}\left(\mathrm{Asp}^{1132}\right)$, and $\mathrm{Asp}^{184}\left(\mathrm{Asp}^{1150}\right)$ form a second triad of invariant amino acids implicated in Mg-ATP-binding. In this triad, $\operatorname{Asp}^{184}\left(\mathrm{Asp}^{1150}\right)$ has the potential to shuttle between the two conserved loops, the glycine-rich loop in the small lobe and the catalytic one in the larger lobe. $\operatorname{Arg}^{1136}\left(\operatorname{Lys}^{168}\right.$ in PKA) provides charge neutralization.

A marked difference between PKA and the insulin receptor is an extended sequence in the C-terminal lobe, termed activation loop. It contains the three major tyrosine autophosphorylation sites, Tyr ${ }^{1158}$, Tyr ${ }^{1162}$, and $\mathrm{Tyr}^{1163}$. The most striking feature of the insulin receptor structure is that one of these residues, Tyr ${ }^{1162}$, is hydrogen-bonded to the catalytic base, $\operatorname{Arg}^{1132}$, and to $\operatorname{Arg}^{1136}$. The phenolic ring of $\operatorname{Tyr}^{1162}$ points to the pyrolidine ring of the conserved $\mathrm{Pro}^{1172}$. Arg $^{1136}$ is also saltbridged to Asp ${ }^{1132}$ and Asp ${ }^{1161}$, and has an axial polar interaction with the indole ring of $\operatorname{Trp}^{1175}$. Together, a network of interactions hold $\mathrm{Tyr}^{1162}$ in a position that blocks access of ATP to the active site. This structure reveals a novel mechanism of $\mathrm{c} / 5$-inhibition in that residues in the activation loop of the unphosphorylated insulin receptor occupy the same space that would otherwise contain ATP. In this way, insertion of Tyr $^{162}$ represses kinase activity by precluding ATP-binding.

From the ternary structure of the insulin receptor and PKA a model for insulin receptor activation has emerged. In this model, an equilibrium must exist between the m-inhibitory conformation and an "open" conformation, in which Tyr ${ }^{1162}$ is disengaged and Mg-ATP can bind. In this transient "open" 
conformation, the kinase can be activated until $\mathrm{Tyr}^{1162}$ returns to the active site. When insulin binds to the receptor, a conformational change in the heterotetrameric receptor places the phosphorylation sites of one $\mathrm{p}$-chain within the active site of the other p-chain. Intramolecular, /ra/w-phosphorylation occurs when $\operatorname{Tyr}^{1162}$ is disengaged andMg-ATP can bind. If phosphorylation occurs on one of the tyrosine residues in the active site, the equilibrium shifts to a conformation in which $\mathrm{Tyr}^{1162}$ is disengaged from the active site and, as a result, the kinase is prone for activation (27). This model points to an essential role for $\mathrm{Tyr}^{1162}$ in insulin receptor kinase activation. $\mathrm{Tyr}^{1162}$ is a highly conserved residue in virtually all trk, and it is proposed that phosphorylated $\mathrm{Tyr}^{1162}$ is salt-bridged to the invariant residue $\operatorname{Arg}^{1131}$, and probably also $\operatorname{Arg}^{1155}$, thus stabilizing the non-inhibiting conformation of the active loop.

Once activated, the kinase /raws-phosphorylates tyrosine residues located within the cytoplasmic part of the receptor. The autophosphorylation of the receptor serves as a molecular switch to induce association and activation of cytoplasmic signaling molecules to the activated receptor.

\section{SIGNAL TRAMSDUCTIOH OF RECEPTOR}

\section{TYROSINE KIHASES}

\section{- $\quad$ Protein-protein interactions}

Receptor-binding proteins all contain one or more copies of a protein module, termed Src homology 2 (SH2) domain, that directly recognize phosphotyrosine containing sequences, and which are responsible for the interaction of receptor-binding proteins with autophosphorylated receptors (29-31). In addition to $\mathrm{SH} 2$ domains, recent studies have identified a second phosphotyrosine-binding domain, termed phosphotyrosine interaction domain (PID) (32). SH2 and PID mediated interactions are important for the activation of signaling pathways initiated by trk. Besides phosphotyrosine binding sequences, the substrates of Rtrk often contain distinct protein modules implicated in the regulation of protein-protein interactions in signal transduction (Fig.3). These domains include SH3 domains (29-31) and pleckstrin homology ( $\mathrm{PH})$ domains (33-36).

\section{Src homology 2 domains}

$\mathrm{SH} 2$ domains have originally been described as regions of homology ( 100 amino acids) between the non-Rtrk c-Src, cFps, and c-Abl, that lie outside the catalytic domain and are not required for kinase activity $(29,30)$. Subsequently, $\mathrm{SH} 2$ domains have also been found in proteins that interact with activated Rtrk, such as phospholipase Cy (PLCy), phosphatidylinositol-3'-kinase $\left(\mathrm{PI}_{3}\right.$,-kinase) and $\mathrm{p} 21^{\text {rai }}$ GTPase activating protein (rasGAP) (37), suggesting that $\mathrm{SH} 2$ domains may be a common feature of proteins that bind to activated Rtrk.
Studies on the $v$-Crk oncogene of the avian sarcoma virus CT10 subsequently show that the $\mathrm{SH} 2$ domain of $v$-Crk interacts with cellular proteins in a tyrosine phosphorylation-dependent manner (38). This implicates $\mathrm{SH} 2$ domains in the regulation of protein-protein interactions by recognizing peptide sequences that encompass tyrosine phosphorylation sites (37).

While $\mathrm{SH} 2$ domains share the common property of binding phosphotyrosine-containing sequences, binding specificity is determined by only a few amino acids located adjacent to the phosphotyrosine. This has been demonstrated by the differential binding of $\mathrm{SH} 2$ domains of the p85a subunit of $\mathrm{PI}_{3},-\mathrm{ki}-$ nase, rasGAP and PLCyto activated growth factor receptors $(39,40)$. Peptide competition and receptor mutagenesis experiments reveal that 3-5 amino acids C-termini to the phosphotyrosine are sufficient to capture the essential elements of sequence-specific recognition (40).

The ternary structure of the $\mathrm{SH} 2$ domains of several proteins has clarified the mechanisms of phosphotyrosine and peptide recognition (41). The ternary structures of the Src, Lck, PLCy, and SH-PTP2 SH2 domains complexed with phosphotyrosine containing peptides $(42,43,44)$, and the solution structures of the SH2 domains of the p85a subunit of PI,,-kinase (45) and c-Abl (46) in absence of bound ligands has been resolved. The obtained ternary structures are strikingly similar and share a common secondary structure framework and considerable similarity in ternary folding. In the ternary structure, the aminoand C-terminal ends of the $\mathrm{SH} 2$ domains are close together in a globular structure, allowing the $\mathrm{SH} 2$ domain to protrude from the rest of the protein, and function independently. ;

The $\mathrm{SH} 2$ domain is composed of two a-helices, termed aA and $\mathrm{aB}$, and seven p-strands, termed PA through PG, located in the order appppppapp (47). The spine of the Src SH2 domain is an uninterrupted p-meander that forms two distinct p-sheets. The sheets are connected by a single continuous $\mathrm{p}$ strand, termed PD, in the central p-sheet and PD' in the second. The central three-stranded antiparallel P-sheet (strands $\mathrm{PB}, \mathrm{pC}$. PD) divides the $\mathrm{SH} 2$ domain into two distinct sides. One side, containing a-helix a A and one face of the central $\mathrm{P}$-sheet, is primarily involved in phosphotyrosine binding. The other side of the $\mathrm{SH} 2$ domain, containing a-helix $\mathrm{aB}$, the smaller P-sheet (strands PD', PE, pF), a long loop termed BG, and the other side of the central P-sheet. is implicated in the binding of three peptide residues C-termini to the phosphotyrosine. The peptide recognition site runs along a flat surface perpendicular to the central P-sheet, whereas the phosphotyrosine is contained in a pocket located on this surface.

The interactions in the phosphotyrosine pocket are very similar between the Lck and Src complex $(43,44)$. The side chain of the phosphotyrosine lies in a deep, elongated groove formed 


\section{Enzymes}

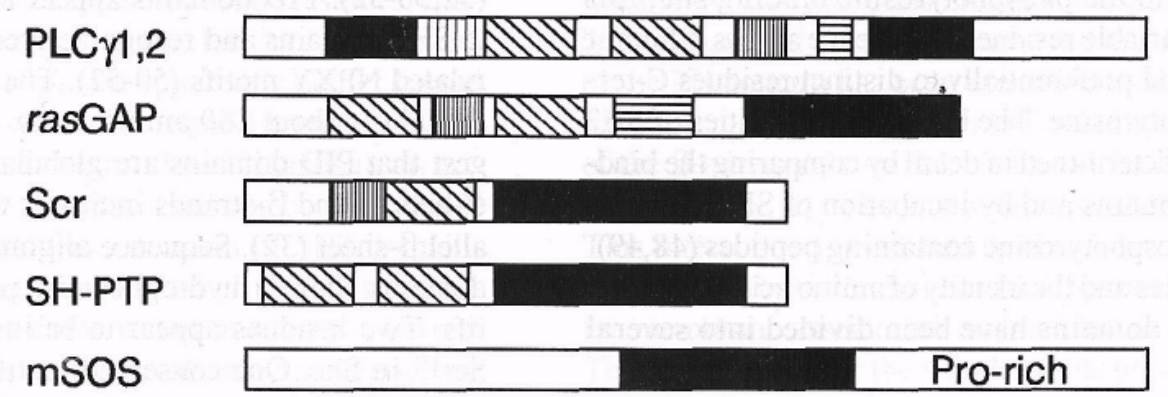

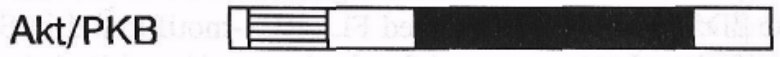

\section{Adaptor proteins}

p85

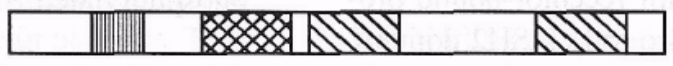

Shc

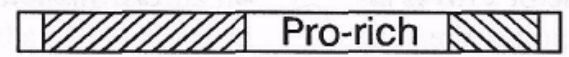

GRB2

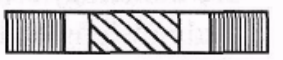

\section{Docking proteins}

IRS-1,-2

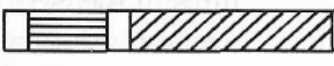

multiple tyr-P sites

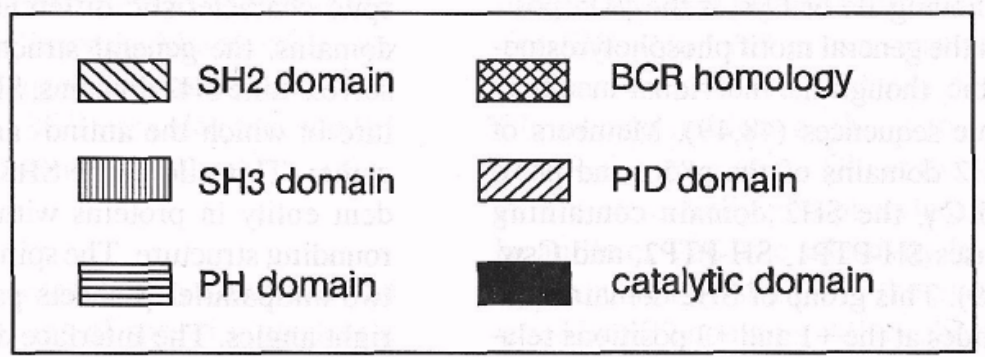

Figure 3. Modular structure of receptor-binding proteins and other proteins involved in signal transduction. The functions and abbreviations of the distinct domains and of the proteins depicted are outlined in the text.

by parts of the PB, PC, and PD strands, the aA helix, and the BCloop ("phosphate-binding" loop). Several highly conserved residues in this pocket interact directly with the bound phosphotyrosine. The side chains of HispD4 and LyspD6 and the main-chain atoms of TyrpD5 form a platform beneath the aromatic ring of the phosphotyrosine. The phosphate moiety is held by a network of hydrogen bonds, in which two arginine residues are of particular importance. ArgocA2 donates four hydrogen bonds to the phosphotyrosine peptide: one to the phosphate oxygen, one amino-aromatic bond to the phosphotyrosine ring, and two to the main chain carbonyl of pY-1. This arginine residue is therefore critical for the conformation of the entire phosphotyrosine residue. The second arginine residue ArgpB5 makes bidentate hydrogen bonds with the phosphate moiety of the phosphotyrosine. 
Besides the conserved phosphotyrosine binding pocket, the structural data indicate that $\mathrm{SH} 2$ domains also possess a pocket for the 3-6 amino acids residues C-termini to the phosphotyrosine. In contrast to the phosphotyrosine binding site, this pocket is lined by variable residues, and hence allows different $\mathrm{SH} 2$ domains to bind preferentially to distinct residues C-termini to the phosphotyrosine. The binding specificities of $\mathrm{SH} 2$ domains have been determined in detail by comparing the binding sites of $\mathrm{SH} 2$ domains and by incubation of $\mathrm{SH} 2$ domains with degenerate phosphotyrosine containing peptides $(48,49)$. Based on these studies and the identity of amino acid pD5 in the $\mathrm{SH} 2$ domain, $\mathrm{SH} 2$ domains have been divided into several categories $(48,49)$.

Group I SH2 domains have a Phe or Tyr at the PD5 position and recognize sequences with the general motif phosphotyrosine-hydrophilic-hydrophilic-hydrophobic $(48,49)$. Members of this group include the 8112 domains of the Src family of non-Rtrk, of rasGAP and growth factor receptor-bound protein 2 (GRB2). Upon binding of the Src or Lck SH2 domain, the hydrophobic residue at the +3 position (He or Pro) is almost completely buried at the hydrophobic binding site. The hydrophilic residues at positions +1 and +2 lie along the surface of the $\mathrm{SH} 2$ domain $(43,44)$.

The SH2 domain in Vav, a guanine nucleotide exchange factor for ras, recognizes the same motif as group ISH2 domains, though the presence of a Thr residue at the PD5 position places Vav in group II (49).

Group III SH2 domains, having He or Cys at the PD5 position, select sequences with the general motif phosphotyrosinehydrophobic-X-hydrophobic, though the individual members of this group select unique sequences $(48,49)$. Members of this group include the $\mathrm{SH} 2$ domains of the p85oc and $\mathrm{p} 85 \mathrm{P}$ subunit of $\mathrm{PI}_{3}$,-kinase, $\mathrm{PLCy}$, the $\mathrm{SH} 2$ domain containing phosphotyrosine phospatases SH-PTP1, SH-PTP2, and Csw, and the She protein $(48,49)$. This group of $\mathrm{SH} 2$ domains primarily binds phosphopeptides at the +1 and +3 positions relative to the phosphotyrosine. In addition to the C-terminal residues, evidence is emerging that also residues amino-termini to the phosphotyrosine may be involved in sequence specific binding of some $\mathrm{SH} 2$ domains.

To date, $\mathrm{SH} 2$ domains have been identified in many proteins, that include enzymes, adaptors, structural proteins, and transcription factors. The binding of activated Rtrk to $\mathrm{SH} 2$ domain-containing proteins provides a mechanism for recruiting substrates and targets to activated Rtrk dimers.

\section{Phosphotyrosine interaction domains}

In addition to $\mathrm{SH} 2$ domains, a distinct PID, also known as
She and IRS-1 NPXY-binding domain (SAIN), has been identified in several proteins, including the adapter protein She, and the insulin receptor substrates (ERS), IRS-1 and IRS-2 (32,50-52). PID domains appear to be structurally unrelated to $\mathrm{SH} 2$ domains and recognize specifically tyrosine phosphorylated NPXY motifs (50-52). The average length of the PID domain is about 160 amino acids. Structure predictions suggest that PK) domains are globular, and the arrangement of a-helices and p-strands indicates the presence of an antiparallel p-sheet (32). Sequence alignments have shown that PID domains share a hydrophobicity pattern and conserved motifs. Two residues appear to be invariant, notably $\mathrm{Gly}^{38}$ and $\mathrm{Ser}^{151}$ in She. One conserved motif located in the ammo-terminal region of the PID domain is reminiscent of the conserved FLVRES-motif found in SH2 domains which is critical for the interaction with phosphotyrosine-containing peptides. Deletion of the FLVRES-like element in the Pro domain of She entirely eliminates the binding of She to tyrosine phosphorylated NPXY motifs (50).

\section{- $\quad$ Src homology 3 domains}

Src homology 3 (SH3) domains are stretches of 55-70 amino acids in length that have been first identified as regions of homology between PLCy, v-Crk, and Src (29,30,37). SH3 domains are now known to be widely distributed among proteins involved in signaling pathways $(29,30,37)$. The crystal structures of the SH3 domains of oc-spectrin (53) and c-Fyn (54), and the solution structures of the $\mathrm{SH} 3$ domains from c-Src (55), $\mathrm{PI}_{3}$,-kinase (56), and PLCy (57) have been resolved. Despite characteristic differences between the individual SH3 domains, the general structure of the $\mathrm{SH} 3$ domains is conserved. Like SH2 domains, SIC domains have a globular structure in which the amino- and C-terminal ends are close together. This allows the SH3 domains to exist as an independent entity in proteins with minimal disruption of the surrounding structure. The spine of the $\mathrm{SH} 3$ domain is formed by two antiparallel p-sheets packed together at approximately right angles. The interface of the sheets forms a hydrophobic core composed of several highly conserved residues. The hydrophobic pocket may serve as a binding site for target proteins.

A number of SH3 domain-binding proteins have been identified, and subsequent sequence comparisons have led to the recognition that a short proline-rich peptide motif of approximately 10 amino acids binds to SH3 domains (58). Screening of combinational libraries of proline-rich peptides identify two classes of peptides as ligands for Src and PL,-kinase SH3 domains (59): class I ligands have a consensus sequence RXLPPZP (Z=L for Src SH3; Z=R for $\mathrm{PI}_{3}$,-kinase SH3), and class II ligands contain a XPPLPXR motif. Structural studies of SH3 domains complexed with proline-rich ligands indicate 
that the bound ligands adopt a left-handed polyproline type II helix (59). In this helix, two prolines interact directly with the surface of the SH3 domain. Other prolines contribute to the formation of the helix, whereas the non-proline residues, consisting of combinations of arginine and leucine, interact extensively with the $\mathrm{SH} 3$ domain and apparently confer ligand specificity. Remarkably, structures of ligand-bound $\mathrm{SH} 3$ domains reveal that $\mathrm{SH} 3$ domains bind class I ligands in an orientation that is opposite to that observed for bound class II ligands (59). This indicates that activation of SH3 domainmediated pathways does not only depend on the subset of sequences bound by the SH3 domain, but also on the correct orientation required for the assembly of an active signalling complex.

\section{- $\quad$ Pleckstrin homology domains}

The pleckstrin homology $(\mathrm{PH})$ domain is a sequence of approximately 120 amino acids homologous to two regions of pleckstrin which is the major PKC substrate in platelets. This region of homology is frequently found in many proteins involved in signaling pathways (33-36). More than $70 \mathrm{PH}$ domain containing proteins have been identified, including serine/ threonine kinases, trk, severeal isoforms of PLC, GAP, nucleotide exchange factors, adaptors, and cytoskeletal proteins (33-

\section{6)}

$\mathrm{PH}$ domains are implicated in intramolecular interactions in signaling pathways. This notion has emerged from the finding that a naturally occurring mutation in the $\mathrm{PH}$ domain of Bruton's tyrosine kinase (Btrk) is sufficient to cause the human genetic disease agammaglobulinaemia. Moreover, in vivo functional analysis of the D. melanogaster guanine nucleotide exchange factor son of sevenless (SOS) revealed that the $\mathrm{PH}$ domain is essential for the development of the D. melanogaster eye.

The crystal structure for the PH domain of dynamin and the solution structure of the $\mathrm{PH}$ domains of spectrin, pleckstrin and dynamin has been determined $(60,61)$. The basic structure of the molecule is an antiparallel p-sheet consisting of seven p-strands, with a long a-helix at the C-terminus. The p-sheet has a strong bend, that is stabilized by the a-helix packing. Opposite this helix are three loops that vary among most PH domains. The overall structure of the $\mathrm{PH}$ domain is electrostatically polarized, with the three variable loops forming a positively charged surface that may serve as a ligand binding site. This positively charged surface includes the position of mutation in the Btrk PH domain.

The structure of the PH domain shows similarity to the structure of lipid-binding proteins. A characteristic shared by all $\mathrm{PH}$ domain-containing proteins is the functional importance of membrane localization (33-36,60). In line with a putative membrane targeting role for $\mathrm{PH}$ domains, fusion proteins containing PH domains of several proteins bind specifically to the negatively charged phospholipid phosphatidyl-inositol-4,5biphosphate (62). In these experiments, the ammo-terminus of the PH domain has been identified as the important site of lipid interaction. In addition to lipid binding, the PH domain of the p-adrenergic receptor kinase- 1 has been demonstrated to bind to the $G_{p y}$ subunits of heterotrimeric $G$ proteins (60). This interaction is mediated by the C-terminus of the $\mathrm{PH}$ domain (60). Both PH domain-binding ligands are neccessary for membrane association and activation of the kinase (60). The requirement for the simultaneous presence of two $\mathrm{PH}$ domain-binding ligands represents a novel mechanism for effecting membrane localization of a protein and may have relevance to other $\mathrm{PH}$ domain-containing proteins.

\section{- Substrates of receptor tyrosine kinases}

The binding of cytoplasmic signaling molecules to autophosphorylated Rtrk provides a mechanism for recruiting substrates and targets to activated Rtrk dimers. The receptor-binding proteins all contain one or more copies of SH2 or PDD domain that directly recognizes the phosphotyrosine-containing binding sites in the autophosphorylated receptor.

The specificity in signaling is provided by sequence specific recognition of phosphotyrosine-containing sequences by $\mathrm{SH} 2$ and PID domains, though appears to be ultimately determined by the catalytic specificity of the trk. Using a degenerate peptide library, with peptides with the sequence Met-Ala-XXXXTyr-XXX-Ala-Lys-Lys as a substrate, the substrate specificity of trk has been investigated (63). Most trk select peptides with Glu or Asp residues at the -4 to -2 positions relative of the Tyr. Rtrk also prefer a Glu at the -1 position, while the nonRtrk preferentially phosphorylate tyrosine residues preceded by an lie or Val. The selectivity for residues C-termini to the Tyr is strikingly similar to the phosphopeptide motifs recognized by SH2 domains. All trk show a selection for hydrophobic residues at the +3 position. Rtrk phosphorylate a general motif Tyr-hydrophobic-X-hydrophobic, a sequence generally recognized by group III SH2 domains as found in the p85 subunit of $\mathrm{PI}_{3}$,-kinase, PLCy, and SH-PTP2 $(48,49)$. In contrast, non-Rtrk show a preference for Tyr-hydrophilic-hydrophilichydrophobic, a sequence recognized by group ISH2 domains $(48,49)$.

As described earlier, $\mathrm{SH} 2$ and Pro domains are found in many proteins. Based on their structural properties, the receptorbinding proteins have been classified into distinct classes (29). The first class of receptor-binding proteins is formed by proteins with known enzymatic activity. The binding of the enzymes to the receptor can facilitate efficient tyrosine phospho- 
rylation leading to activation of the enzyme, or may induce allosteric activation of the bound enzyme. Members of this class include PLCy, rasGAP, $\mathrm{SH} 2$ domain containing protein tyrosine phosphatases, and non-Rtrk. The second class of receptor-binding proteins, termed adaptors, are devoid of any enzymatic activity. These proteins are often composed of $\mathrm{SH} 2$ and $\mathrm{SH} 3$ domains, and function as intermediates between Rtrk and downstream signaling molecules. Members of the adaptors family include the p85 subunit of $\mathrm{PI}_{3}$,-kinase, GRB2, Crk, Nek, and She. Docking proteins represent the third class of receptor-binding proteins. They have no enzymatic activity, but act as an Rtrk surrogate by providing multiple $\mathrm{SH} 2$ domain binding sites following tyrosine phosphorylation by an activated Rtrk. Members of this class include IRS-1 and IRS-

The recruitment of $\mathrm{SH} 2$ or PID domain-containing proteins to activated Rtrk or to a tyrosine phosphorylated docking protein represents the first step in the activation of signaling cascades. The best characterized signaling pathways in fibroblasts initiated by activated Rtrk are described below.

\section{- $\quad$ Activation of the p21"'" signaling pathway}

The p2 1 "' genes are the cellular counterparts of the transforming genes of the Harvey and Kirsten strains of rat sarcoma virus, and of the transforming gene of a neuroblastoma cell line. The products of the $\mathrm{p} 21^{\mathrm{TM}}$ genes are small GTP-binding proteins of approximately $21 \mathrm{kD}$ localized at the inner side of the plasma membrane. By analogy to other GTP-binding proteins, p2 1 "" cycles between an inactive GDP-bound state and an active GTP-bound state (Fig. 4) (64-66). In the oncogenic forms of $\mathrm{p} 21^{\mathrm{TO}}$ which have been detected in a variety of human tumors, point mutations at positions 12,13 or 61 lock the protein in a constitutively activated GTP-bound state (67).

Genetic evidence from D. melanogaster and C. elegans, microinjection studies with neutralizing antibodies and overexpression of $\mathrm{p} 21^{\text {ras }}$ proteins in fibroblasts have placed $\mathrm{p} 21^{\prime *}$ in signal transduction downstream of Rtrk (2). A wide variety of growth factors increase the intracellular levels of p21""-GTP (2). Moreover, cells expressing oncogenic forms of trk such as $v$-Src, $v$-Abl, oiv-ErbB2 also exhibit increased levels ofp $21^{\text {ral }}$ GTP (2).

The p2 1 "* guanine nucleotide content can be regulated at two levels. First, at the level of exchange of GDP for GTP by guanine nucleotide exchange factors (GNEF) (Fig.4). Second, at the level of hydrolysis of p21""-GTP, a process catalyzed by GTPase activating proteins (GAP) (64-66,68) (Fig.4). Evidence has been obtained that growth factors enhance the exchange rate of GDP-bound to $\mathrm{p} 21^{\text {ray }}$ by exogeneous guanine nucleotides, indicating an involvement of GNEF in the formation of p21 TM_GTP $(69,70)$. Based on homology with the catalytic domain of $S$. cerevisiae and D. melanogaster GNEF for ras (cdc25 and SOS protein, respectively), several putative mammalian GNEF have been identified, including mSOS (71). Despite the cloning of GNEF, the mechanism by which activated trk couple to p21"'" remains unclear, though the identification of the GRB2 protein contributes to the elucidation of the activation mechanism.

GRB2 was originally identified by screening a protein expression library with the autophosphorylated C-terminal tail of the EGFR and by screening a cDNA library with degenerate oligonucleotides recognizing SH2 domains (72). GRB2 encodes a $23 \mathrm{kD}$ protein that is devoid of any enzymatic function and consists almost entirely of two SH3domains separated by one $\mathrm{SH} 2$ domain. Genetic counterparts for GRB2 have been isolated from $C$. elegans (Sem-5; sex muscle abnormal) and $D$. melanogaster (Drk; downstream of receptor kinases) (73-75).

GRB2 associates through its SH2 domain to tyrosine phosphorylated phosphotyrosine-hydrophilic-hydrophilic-hydrophobic sequences with a strong preference for Asn at the +2 position (49). Many activated Rtrkbind GRB2 directly, though in some cases the binding of GRB2 requires an adaptor protein, such as She, SH-PTP2, RPTPoc, IRS-1 or IRS-2 (2). An involvement of GRB2 in the regulation of p21"' comes from the observation that overexpression of GRB2 enhances the activation of p21"K by EGF (76) and the activation of ERK2 by insulin (77). Moreover, coinjection of GRB2 together with $\mathrm{P} 21^{\mathrm{TM}^{1}}$ leads to the induction of DNA synthesis in quiescent fibroblasts, while injection of GRB2 or $\mathrm{p} 21^{\text {rai }}$ alone has no effect (72). Also genetic evidence from $C$. elegans places GRB2 in a pathway upstream of p21"'". GRB2 is the mammalian homologue of the $C$. elegans Sem-5 (73). In C. elegans, the induction of vulval differentiation is regulated by the Let- 23 trk and the Let- 60 ras protein. Mutation of the Sem-5 allele abrogates vulval development, and experimental evidence places Sem-5 downstream of Let-23 and upstream of Let-60 (73).

Genetic analysis of the D. melanogaster Drk protein suggests that Drk function is essential for signaling of the sevenless Rtrk that mediates proper specification of the R7 photoreceptors in the $D$. melanogaster eye $(74,75)$. In these studies, the biological activity of Drk correlates with the binding of the Drk SHE domain to the activated sevenless receptor and concomitant localization to the plasma membrane. A major breakthrough in the investigation of the mechanism for linking trk to $\mathrm{p} 21^{\text {rai }}$ is the finding that Drk SH3 domains bind in vitro to proline-rich sequences in the C-terminal tail of SOS $(74,75)$. SOS is a $D$. melanogaster guanine nucleotide exchange factor which is, like ras and Drk, required for sevenless signaling (71). 


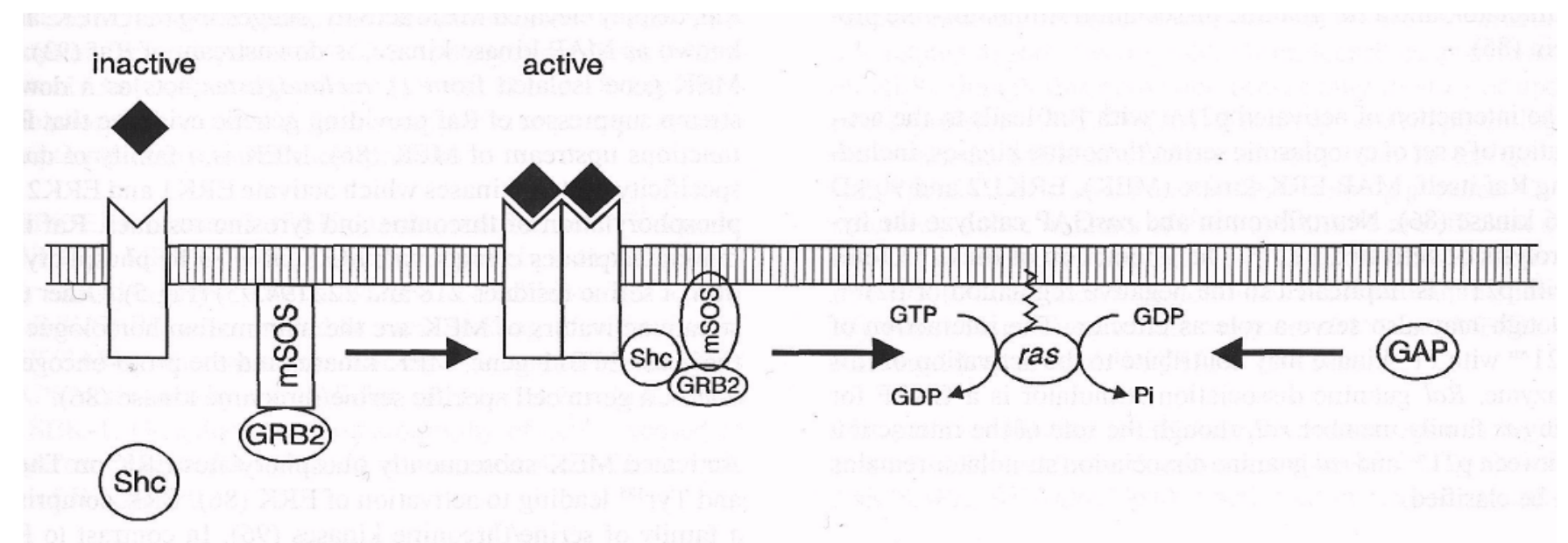

Figure 4. Regulation ofp $21^{\text {ras }}$ guanine nucleotide content by receptor tyrosine kinases. Upon ligand induced activation of receptor tyrosine kinase, She can bind to phosphotyrosine residues within the activated receptor. The activated receptor tyrosine kinase induces tyrosine phosphorylation of She which is followed by the association ofGRB2. Alternatively, GRB2 can bind directly to an activated receptor tyrosine kinase. The SH3 domain ofGRB2 is bound to the C-terminal tail of mSOS. The interaction of GRB2/mSOS with phosphotyrosine residues probably induces a conformational change that relieves the inhibitory constraint of the $C$-terminal tail ofmSOS. In this way, active $\mathrm{mSOS}$ can promote the exchange of GDPfor GTP on $221^{\text {ras }}$. p2 $21^{m}$-GTP is inactivated by hydrolysis ofGDP to GTP which is catalyzed by GTPase activating proteins $(G A P)$.

\begin{abstract}
Subsequently, it has been demonstrated that GRB2 binds to the mammalian homolog of SOS (mSOS) and that this complex exists constitutively (78-82). From this result, it has been proposed that the binding of the GRB2/mSOS complex to an activated Rtrk translocates mSOS to the vicinity of membranebound p21"'. As a result of this translocation,the exchange of GDP for GTP on $p 2 l^{\mathrm{TM}}$ may be stimulated (Fig.4).
\end{abstract}

In vivo structure-function analysis of SOS reveals that the amino-terminus of SOS is essential for its function in $D$. melanogaster. The amino-terminal region contains a $\mathrm{PH}$ domain which is implicated in membrane binding. In line with this membrane recruitment model, modified mSOS proteins that are constitutively located at the plasma membrane activate the $p 2 l^{\prime \prime \prime \prime}$ signaling pathway without external stimuli. These membrane-targeted mSOS derivatives are even more active upon deletion of the $\mathrm{C}$-terminal region, the binding site for the GRB2 SH3 domains. This suggests that a secondary activation mechanism may rely on a conformational change induced by binding of GRB2/mSOS to tyrosine phosphorylated proteins that relieves the inhibitory effect of the C-terminal domain of mSOS (Fig. 4).

Besides interacting with activated Rtrk, the 8112 domain of GRB2 also binds to tyrosine phosphorylated Src-homology collagen (She) (83). The primary structure of She contains an amino-terminal PID domain and a C-terminal SH2 domain separated by a glycine/proline-rich motif with regions of homology to the a,-chain of collagen $(50,51,83)$. She has been implicated in p21"* activation, since its overexpression transforms cells and induces p21 "'--dependent neurite outgrowth $(83,84)$. She interacts with several activated Rtrk through its PID and/or SH2 domain (2), and as a result She becomes tyrosine phosphorylated. Tyrosine phosphorylated She associates with GRB2/mSOS (84) (Fig.4). This interaction is presumably mediated by the binding of the GRB2 SH2 domain to a tyrosine phosphorylated YVNV motif within the She protein. In this way, the interaction of tyrosine phosphorylated She with GRB2/mSOS provides an alternative mechanism for the activation of the $\mathrm{p} 21^{\prime \prime} \mathrm{k}$ signaling pathway by Rtrk.

\section{Effectors of $\mathrm{p} 21^{\mathrm{TM}}$}

Activated $\mathrm{p} 21^{\mathrm{OT}}$ exerts its effects by interacting with one or more cellular effector molecules. Mutations in $\mathrm{p} 21^{\mathrm{TM}}$ which abrogate its biological activity without reducing GTP-binding have delineated a domain in $\mathrm{p} 21^{\mathrm{TM}}$ that associates with effector molecules, termed effector domain, to a region between amino acids 35-40. Among the proteins that physically interact with the effector domain in a GTP-dependent manner are 
neurofibromin, Raf , PL,-kinase, a ral guanine dissociation stimulator, and a ral guanine dissociation stimulator-like protein (85).

The interaction of activated P21"* with Raf leads to the activation of a set of cytoplasmic serine/threonine kinases, including Raf itself, MAP-ERK-kinase (MEK), ERK1/2 and $90 \mathrm{kD}$ S6 kinase (86). Neurofibromin and rasGAP catalyze the hydrolysis of activated $\mathrm{p} 21$ "*. The interaction of these proteins with pll"'" is implicated in the negative regulation of $\mathrm{p} 21^{\text {rai }}$, though may also serve a role as effector. The interaction of p21"* with $\mathrm{PI}_{3}$,-kinase may contribute to the activation of this enzyme. Ral guanine dissociation stimulator is a GNEF for the ras family member ral, though the role of the interaction between $\mathrm{p} 21$ "* and $\mathrm{ral}$ guanine dissociation stimulator remains to be clarified.

\section{- $\quad$ Activation of the Raf/MEK/ERK pathway}

As described above, GTP-bound p21"" interacts with the amino-terminal domain of the serine/threonine kinase Raf (8789). However, p21 $1^{\text {ras }}$-GTP does not stimulate the kinase activity of Raf in vitro (88). Furthermore, purified active Raf is not associated with p21 ${ }^{\mathrm{rar}}$ and thus appears to be locked into the active state through a covalent modification, or through highaffinity interaction with an unknown regulator (90). This raises the possibility that p21"' functions as a regulated, membranebound anchor to recruit Raf to the plasma membrane. Indeed, modified Raf proteins that associate with the plasma membrane are constitutively active, and under these circumstances independent of $p^{\mathrm{TM}}(91,92)$.

However, several lines of evidence point to an involvement of additional factors in the activation of Raf. First, growth factors can further activate membrane-bound Raf via a mechanism independent of P21"'" (91). This suggests that other kinases are required for full activation and phosphorylation of Raf. Second, once deposited to the plasma membrane, Raf becomes associated with structural elements as it cannot be released from the plasma membrane with detergent (92). These components are expected to contain the missing link that lock Raf in its kinase-active state.

A putative group of proteins that may contribute to Raf activation are members of the family of 14-3-3 proteins. The 14-3-3 $\mathrm{P}$ and 14-3-3 $£$ isoforms interact with both the amino-terminal and the kinase domain of Raf, though without interfering with the binding of Raf to p21 $1^{\mathrm{TM}_{-} \mathrm{GTP}}$ (90). 14-3-3 proteins associate with Raf in mammalian cells and accompany Raf to the plasma membrane during the process of activation. Moreover, both 14-3-3 (3 and 14-3-3 $£$ activated Raf in vitro, thus suggesting that 14-3-3 proteins may participate in or be required for activation of Raf.
Cells transformed with v-Raf, or the oncogenic mutants of cRaf, display elevated MEK activity, suggesting that MEK, also known as MAP kinase kinase, is downstream of Raf (93). A MEK gene isolated from D. melanogaster acts as a downstream suppressor of Raf providing genetic evidence that Raf functions upstream of MEK (86). MEK is a family of dualspecificity protein kinases which activate ERK1 and ERK2 by phosphorylation of threonine and tyrosine residues. Raf immunoprecipitates can activate MEK in vitro by phosphorylation of serine residues 218 and 222 (94,95) (Fig.5). Other upstream activators of MEK are the mammalian homologue of the yeast STE11 gene, MEK kinase, and the proto-oncogene $c$-mos, a germ cell specific serine/threonine kinase (86).

Activated MEK subsequently phosphorylates ERK on $\mathrm{Thr}^{183}$ and $\mathrm{Tyr}^{185}$ leading to activation of ERK (86). ERK comprises a family of serine/threonine kinases (96). In contrast to Raf and MEK, ERK appears to have multiple substrates, including phospholipase A2, $90 \mathrm{kD}$ S6 kinase, the transcription factors myc, fun, Elk-1, and PHAS-I (96). ERK also phosphorylates mSOS which may represent a negative feedback of the p21 TMVERK pathway (97).

\section{- $\quad$ Activation of the JNK/SAPK and other MAPK pathways}

In addition to the p21 "'/Raf/MEK/ERK pathway, several MAP kinase (MAPK)-related pathways have been characterized (Fig.5). These pathways are regulated by a three-component protein kinase cascade consisting of a serine/threonine protein kinase (MAPKKK), which phosphorylates and activates a dual-specificity kinase (MAPKK) that in turn activates another serine/threonine kinase (MAPK). The MAPK serve to link signals from the plasma membrane to the cytosol and the nucleus, and are implicated in the regulation of cell shape, osmotic integrity, and pheromone responses in yeast, stress responses in mammalian cells, and cytokine signaling (96). In mammalian cells, at least three MAPK-related families exist, including the jun $\mathrm{N}$-terminal/stress-activated protein kinase (JNK/SAPK), /bs-regulating kinase (FRK), andMAPKAPkinase-2 reactivating kinase (RK/MPK2/p38 ) (96). These subgroups are distinguished by the sequence of the tripeptide dual specificity phosphorylation motif that is required for activation: Thr-Glu-Tyr (ERK), Thr-Pro-Tyr (JNK/SAPK), andThrGly-Tyr (RK/MPK2/p38).

The JNK/SAPK family comprises several isoforms, the human $46 \mathrm{kD}$ JNK1 and $54 \mathrm{kD}$ JNK2 protein, and the rat p54a, p54p, and p54y SAPKs (98). JNK/SAPK are potently activated in response to cellular stress, ultraviolet radiation, incubation with protein synthesis inhibitors, genotoxic agents, interleukin-1 and tumor necrosis factor-a (TNF-a), and to a lesser extent by oncogenic $\mathrm{p} 21^{\mathrm{OT}}$, EOF andNGF. The activation of JNK/SAPK by EOF and by NGF depends on p 21 "', whereas JNK/SAPK ac- 
tivation by TNF-a is $\mathrm{p} 21^{\mathrm{TO}}$-independent $(96,98)$. JNK/SAPK binds to the ammo-terminal transactivation domain of the transcription factors $c$-jun and ATF-2, and phosphorylates serines 63 and 63 of $c$-jun and threonines 69 and 71 of ATF-2 $(96,98)$. The phosphorylation of ATF-2 and c-jun is implicated in transcriptional activation of these proteins.

SAPK/ERK kinase-1 (SEK-1), also known as JNK kinase (JNKK or MKK4), a dual-specificity protein kinase structurally related to MEK, phosphorylates the Thr ${ }^{183}$-Pro-Tyr ${ }^{185}$ motif of JNK/SAPK in vitro and in vitro leading to activation of JNK/SAPK, whereas an inactive SEK-1 mutant blocks JNK/ SAPK activation by extracellular stimuli $(96,98)$. In addition to SEK-1, Q-sepharose chromatography of cells exposed to hyperosmolar media indicate the existence of another activator of JNK/SAPK.
SEK-1 on its turn is activated through phosphorylation by MEKK $(96,98)$. MEKK, a serine/threonine kinase structurally related to Raf, has originally been identified as activator of MEK, though this activation occurs only in vitro or upon overexpression of MEKK (86). When expressed at physiological levels, no MEK activation can been seen. In analogy to Raf, MEKK is activated by small GTP-binding proteins. Constitutively active mutants of Racl and Cdc42 are efficient activators of the kinase cascade leading to JNK/SAPK activation $(99,100)$. Studies with dominant negative mutants identify Racl as an intermediate between P21"* and MEKK in Rtrk signaling toward JNK/SAPK $(99,100)$.

The pathway leading to RK/MPK2/p38 activation is highly related to the pathway regulating JNK/SAPK (Fig.5). Like JNK/SAPK, RK/MPK2/p38 is activated in response to cellu-

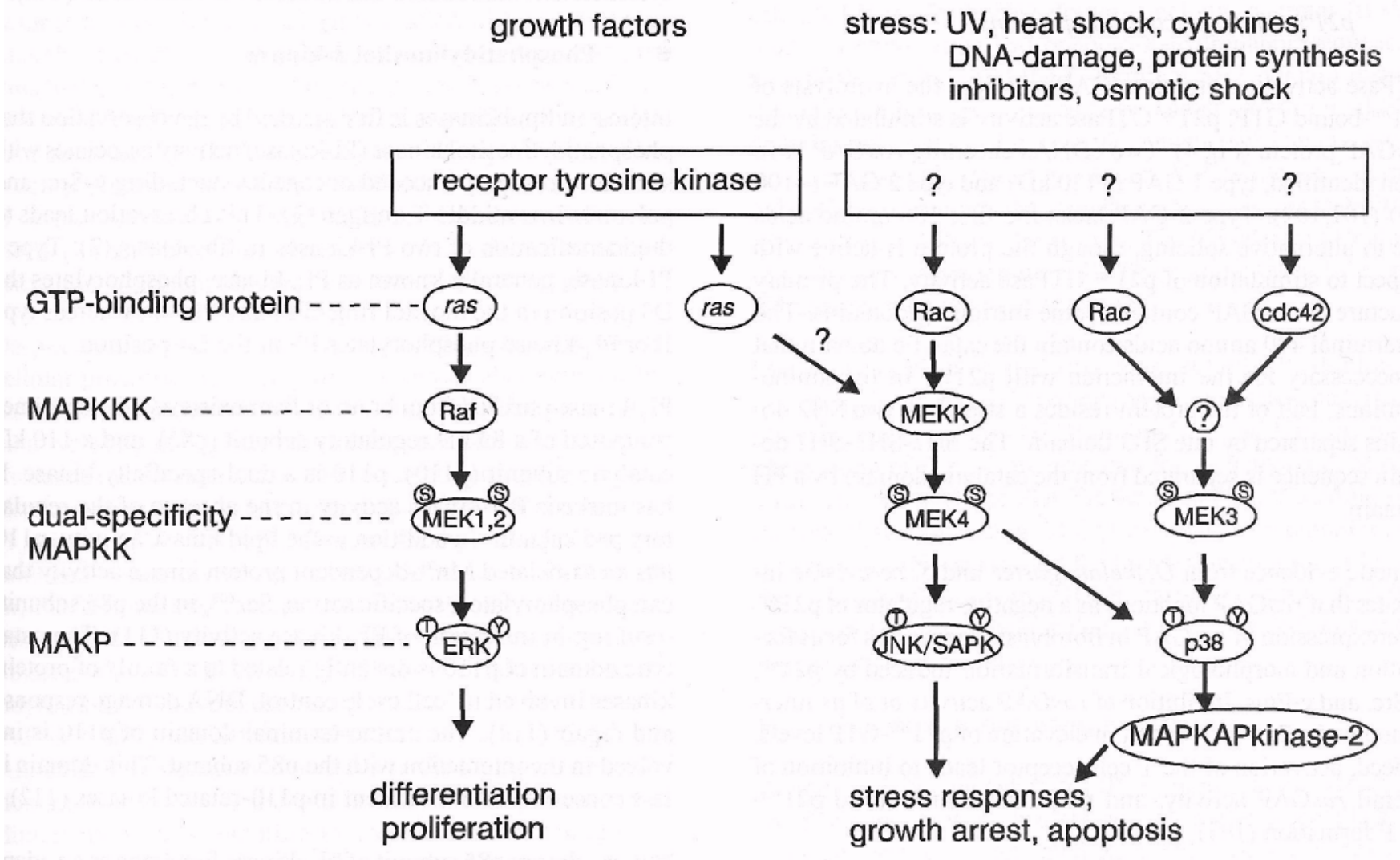

Figure 5. MAP kinase pathways in mammalian cells. MAP kinase pathways in mammalian cells contain a central core of GTP-binding protein, a serine/threonine kinase (MAPKKK), a dual-specificity kinase (MAPKK) and a serine/threonine kinase (MAPK). The activation of the ERK pathway is implicated in proliferation and differentiation, while JNK/SAPK and p38 are involved in the regulation of stress responses and apoptosis. 
lar stress, such as heat shock or osmotic stress, and by interleukin-1 (98). The activation of RK/MPK2/p38 leads to activation of MAPK-activated protein kinase-2 (MAPKAP kinase-2) which subsequently phosphorylates small heat shock proteins (98). Activation of RK/MPK2/p38 is mediated by

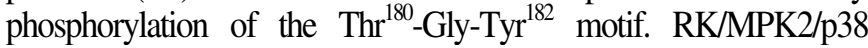
is specifically activated by the dual-specificity kinase MKK3 (98). Also SEK-1 activates RK/MPK2/p38 in vitro, though coexpression of SEK-1 and its activator MEKK does not lead to a marked activation of RK/MPK2/p38 (98). This implicates a novel uncharacterized MEKK related protein kinase in the regulation of the RK/MPK2/p38 kinase cascade. Upstream of the MEKK-related protein kinase lies the small GIF-binding proteins Racl and Cdc42 $(99,100)$.

Other putative p21 "'-dependent MAPK pathways include FRK (96), which phosphorylates the transactivation domain of Fos, and an unidentified kinase responsible for the phosphorylation of CREB in response to NGF (96).

\section{- $\quad$ p21 $^{\text {ras }}$ GTPase activating proteins}

GTPase activating proteins (GAP) catalyze the hydrolysis of p21"'--bound GTP. p21 ${ }^{\mathrm{TM} *}$ GTPase activity is stimulated by the rasGAP protein (Fig.4). Two cDNAs encoding rasGAP have been identified, type 1 GAP $(-120 \mathrm{kD})$ and type 2 GAP $(-100$ kD) $(101,102)$. Type 2 GAP lacks the first 180 amino acids due to alternative splicing, though the protein is active with respect to stimulation of $\mathrm{p} 21^{\mathrm{r}<1}$ GTPase activity. The primary structure of rasGAP contains some intriguing domains. The C-terminal 400 amino acids contain the catalytic domain that is neccessary for the interaction with $\mathrm{p} 21^{\mathrm{raj}}$. In the aminoterminus, half of the protein resides a stretch of two 8112 domains separated by one $\mathrm{SH} 3$ domain. The $\mathrm{SH} 2-\mathrm{SH} 3-\mathrm{SH} 2$ domain sequence is separated from the catalytic domain by a $\mathrm{PH}$ domain.

Genetic evidence from $D$. melanogaster and $S$. cerevisiae indicates that rasGAP functions as a negative regulator of $\mathrm{p} 21^{\mathrm{r}}<*$. Overexpression of rasGAP in fibroblasts suppresses focus formation and morphological transformation induced by $\mathrm{p} 21^{\mathrm{n} "}$, v-Src. and v-Fms. Inhibition of rasGAP activity or of its interaction with p21"* may result in elevation of p21 ${ }^{\mathrm{m}}$-GTP levels. Indeed, activation of the $\mathrm{T}$ cell receptor leads to inhibition of overall rasGAP activity, and may thus contribute to $\mathrm{p} 21^{\mathrm{r}<1}-$ GTP formation (103).

The $\mathrm{SH} 2$ domains of rasGAP are implicated in the interaction of rasGAP with activated Rtrk, including PDGFR, EGFR, insulin receptor, and HGFR (2). Upon this association, rasGAP becomes tyrosine phosphorylated and associates with two other phosphoproteins, p62 and p!90 (104). Cells expressing mutant PDGFR that lack rasGAP binding site, display normal
p21ras-GTP formation, suggesting that this interaction is not involved in the process (40).

Although rasGAP has been purified as a negative regulator for $\mathrm{p} 21 " *$, rasGAP may also contribute positively to signaling. Expression of the $\mathrm{SH} 2-\mathrm{SH} 3-\mathrm{SH} 2$ stretch of rasGAP inhibits opening of $\mathrm{K}^{*}$ channels in atrial cell membrane, and induces the expression of $c$-fos promoter-driven luciferase gene $(105,106)$. The effector functions of rasGAP may involve the formation of a complex between rasGAP and p62 and pi90 (104). p62 shows homology with a putative hnRNP protein (GRP33), and recombinant p62 binds to RNA and DNA in vitro, suggesting a role for p62 in RNA and DNA metabolism (107). p!90 that binds to the SH3 domain of rasGAP has a region homologous n-chimerin and rho-GAP (108). It has been shown that $\mathrm{p} 190$ has GTPase activity toward Rho, a small GTPbinding protein implicated in actin stress fiber formation (109), and that expression of the rasGAP SH2-SH3-SH2 stretch and association with pi90 correlates with changes in the cytoskeleton and reduces cell adhesion to fibronectin (110).

\section{- $\quad$ Phosphatidylinositol 3-kinase}

Interest in lipid kinases is first sparked by the observation that phosphatidylinositol kinase (Pl-kinase) activity associates with several retrovirally encoded oncogenes, including $\mathrm{v}-\mathrm{Src}$, and polyomavirus middle $\mathrm{T}$ antigen (2). This observation leads to the identification of two Pl-kinases in fibroblasts (2). Type I $\mathrm{Pl}$-kinase, generally known as $\mathrm{PI}_{3}$,-kinase, phosphorylates the D3 position in the inositol ring of $\mathrm{PI}$ and $\mathrm{PI}(4) \mathrm{P}$, whereas type II or $\mathrm{PI}_{4}$-kinase phosphorylates PI on the $\mathrm{D} 4$ position.

$\mathrm{PI}_{3}$,-kinase purified from brain or liver exists as a heterodimer composed of a $85 \mathrm{kD}$ regulatory subunit (p85), and a $110 \mathrm{kD}$ catalytic subunit (pi 10). pi 10 is a dual-specificity kinase. It has intrinsic $\mathrm{PI}_{3}$,-kinase activity in the absence of the regulatory p85 subunit. In addition to the lipid kinase activity, pi 10 has an associated $\mathrm{Mn}^{2+}$-dependent protein kinase activity that can phosphorylate a specific serine, $\operatorname{Ser}^{608}$, in the p85 subunit, resulting in inhibition of $\mathrm{PI}_{3}$,-kinase activity (111). The catalytic domain of pi 10 is distantly related to a family of protein kinases involved in cell cycle control, DNA damage response and repair (112). The amino-terminal domain of pi 10 is involved in the interaction with the p85 subunit. This domain is less conserved or even absent in pi 10-related kinases (112).

The regulatory p85 subunit of $\mathrm{PI}_{3}$,-kinase functions as an adaptor linking tyrosine phosphorylated Rtrk to $\mathrm{PI}_{\mathrm{y}}$-kinase activation (113). The primary sequences of p85 a and p85 [3 isoforms reveal a multidomain structure containing a number of noncatalytic domains. At the amino-terminus of the protein lies a $\mathrm{SH} 3$ domain followed by a region with significant sequence homology to the product of the breakpoint cluster region (BCR) 
gene. This region of BCR has GTPase-activating activity toward the small GTP-binding protein Rac (113). The C-terminal half of the molecule is dominated by two $\mathrm{SH} 2$ domains (113). The region between the $\mathrm{SH} 2$ domains contains the binding site for pi 10 subunit (113). Ser ${ }^{608}$ which is phosphorylated by pi 10 subunit is located in this region and is implicated in the regulation of $\mathrm{PI}_{3}$,-kinase activity (111). In addition, the p85 subunit contains two binding sites for SH3 domains (2). Binding of SH3 domains of non-Rtrk to purified $\mathrm{PI}_{3}$,-kinase leads to activation of the enzyme (2). The $\mathrm{SH} 2$ domains of the $\mathrm{p} 85$ subunit mediate the binding of $\mathrm{PI}_{3}$,-kinase to phosphotyrosine residues in activated Rtrk or in so-called adaptor molecules, such as IRS-1 and IRS-2 (2). The p85 SH2 domains recognize a tyrosine phosphorylated YXXM motif (48), and both $\mathrm{SH} 2$ domains are required for stable binding. The association between Rtrk and p85 subunit is stimulated by numerous growth factors, and results in allosteric activation of theholoenzyme.

The involvement of active $\mathrm{PI}_{3}$,-kinase and 3'-phosphoinositide metabolites in cellular signaling is studied with receptor mutants that lack $\mathrm{PI}_{3}$,-kinase binding sites, with mutant p85 proteins that lack the pi 10 binding site, and using the specific inhibitors of PI, -kinase activity. From these studies, evidence has been obtained that $\mathrm{PI}_{3}$,-kinase may lie on the pathway leading to cell proliferation $(40,114,115)$. Furthermore, activation of PI,-kinase is apparently required for insulin, IGF-1, HGF, and PDGF (2). This observation fits with a role for $\mathrm{PI}_{3}$,-kinase in Rac activation, a protein regulating membrane ruffling (113).

Despite evidence for an involvement of $\mathrm{PI}_{3}$,-kinase in several cellular processes, relatively little is known about the mechanisms that transmit the signal beyond this pointRecently, a putative target of 3'-phosphoinositides has been characterized. Evidence indicates that the $60 \mathrm{kD}$ serine/threonine kinase Akt, also known as PKB or Rac, lies on a pathway downstream of PI,--kinase (116): (/') activation of Akt by growth factors is inhibited by wortmannin, a specific inhibitor of PI,, -kinases, (ii) PDGFR mutants that fail to activate $\mathrm{PI}_{3}$,-kinase also fail to activate Akt/PKB, (Hi) a dominant negative mutant of PI,,kinase inhibits PDGF activation of Akt/PKB, and (iv) phosphatidylinositol-3-monophosphate (PtdIns3P), but not Ptdlns or PtdIns(4,5)P2, can activate Akt/PKB in vitro. Activation of $\mathrm{Akt} / \mathrm{PKB}$ is inhibited by mutations in the amino-terminal $\mathrm{PH}$ domain (116). As this domain is essential for protein homodimerization, it is tempting to speculate that binding of 3'phosphoinositides to the $\mathrm{PH}$ domain can promote dimerization of $\mathrm{Akt} / \mathrm{PKB}$ and so activate it, possibly by inducing protein autophosphorylation.

Among the potential targets of Akt/PKB is the $70 \mathrm{kD}$ S6 kinase. p70 S6 kinase is activated by constitutively active Akt/ $\mathrm{PKB}$ in vivo (116). In addition, growth factor induced activa- tion of p70 S6 kinase is inhibited by $\mathrm{PI}_{3}$,-kinase inhibitors $(117,118)$. However, PDGFR mutants that fail to activate $\mathrm{PI}_{3}$,kinase and Akt/PKB still activate p70 S6 kinase $(117,118)$, suggesting that several pathways contribute to the activation of this enzyme (118).

\section{- $\quad$ Phospholipase Cy}

Activation of phospholipase Cy (PLCy) induces the hydrolysis of phosphatidylinositol 4,5-diphosphate $\left(\mathrm{PIP}_{2}\right)$ to diacylglycerol (DAG) and inositol 1,4,5-trisphosphate $\left(\mathrm{IP}_{3}\right)$. DAG is the physiological activator of PKC, whereas IP, mobilizes $\mathrm{Ca}^{2+}$ from intracellular stores, thereby affecting $\mathrm{Ca}^{\mathrm{w}}$-dependent intracellular processes.

The primary structure of PLCy, which is similar in its two known isoforms (PLCyl and PLC y2), contains two central SH2 domains and a SH3 domain C-terminus to the central $\mathrm{SH} 2$ domain. This $\mathrm{SH} 2-\mathrm{SH} 2-\mathrm{SH} 3$ structure is flanked by a split $\mathrm{PH}$ domain. The SH2 domains of PLCy direct the interaction with activated Rtrk. Both SH2 domains belong to group III that bind phosphotyrosine-hydrophobic-X-hydrophobic sequences, though the amino- and the C-terminal SH2 domain display different binding specificities (48). The amino-terminal SH2 domain preferentially binds to the sequence phosphotyrosineIle/Leu/Val-acidic (Glu/Asp)-Ile/Leu/Val, while the C-terminal SH2 domain binds the sequence phosphotyrosine-Val/Ilehydrophobic (Ile/Leu)-Pro/Ile/Val. The SH3 domain localizes PLCy to the cytoskeleton (119). The significance of the split $\mathrm{PH}$ domain remains to be clarified.

Most but not all activated Rtrk bind PLCyl (2). Binding of PLCyl to the activated Rtrk apparently facilitates the tyrosine phosphorylation of PLCyl. Both binding and tyrosine phosphorylation of PLCyl are essential for its activation. Studies with mutant FGFR and PDGFR that lack PLCyl binding sites indicate that activation of PLCyl per se is not required for the induction of DNA synthesis (2). However, restoration of $\mathrm{Tyr}^{1021}$, the PLCyl binding site in PDGFR, partially restores DNA synthesis (114). This indicates that activation of PLCy itself can induce a mitogenic response.

\section{- $\quad$ Protein tyrosine phosphatases}

Protein tyrosine phosphatases (FTP) represent a diverse family of enzymes that catalyze the dephosphorylation of phosphotyrosine residues in activated Rtrk and their substrates. PTP can be divided into two groups. One group comprises receptor-like PTP, that contain a putative extracellular ligand binding domain, a transmembrane domain and a highly conserved cytoplasmic catalytic domain $(120,121)$. The other group is formed by a large expanding family of cytoplasmic PTP $(120,121)$. Within the family of cytoplasmic PTP, two PTP 
have been characterized that contain $\mathrm{SH} 2$ domains, termed SH-PTP1 and SH-PTP2 (120,121).

The primary structure of SH-PTP1, also known as FTP 1C, SHP, and HCP, indicates the presence of two amino-terminal SH2 domains and a C-terminal catalytic domain (122). The expression of SH-PTP1 is limited to lymphocytes. The aminoterminal SH2 domain of SH-PTP1 recognizes a broad selection of phosphotyrosine-hydrophobic-X-hydrophobic sequences with a slight preference for Phe at the +1 and +3 position relative to the phosphotyrosine (49). The optimal binding motif for the $\mathrm{C}$-terminal $\mathrm{SH} 2$ domain has not been determined yet. The amino-terminal $\mathrm{SH} 2$ domain of SH-PTP1 associates in vitro with tyrosine phosphorylated EOF and SCF receptors (122). Expression of SH-PTP1 in 293 cells induced a partial or complete dephosphorylation of the EGFR, ErbB2, overexpressed PDGFRoc and PDGFRp, and the P subunits and unprocessed precursors of the insulin and IGF-1 receptor (123). No direct interaction between CSF-1 receptor and SH-PTP1 could be demonstrated (2). Despite this, SH-PTP1 has been identified as a tyrosine phosphorylated protein in macrophages incubated with CSF-1 (2). In vivo, SH-PTP1 is probably involved in attenuation of the mitogenic response in macrophages, as macrophages isolated from mice homozygous for the motheaten locus, which encodes the SH-PTP1 gene, show CSF1 independent proliferation (2).

SH-PTP2, also known as PTP1D, PTP2C, Syp, or SH-PTP3, has a primary structure similar to SH-PTP 1 (123). The aminoterminal $\mathrm{SH} 2$ domain recognizes phosphotyrosine-hydrophobic-X-hydrophobic sequences with a small preference for He or Val at the +1 position, and a Val, lie, Leu, or Pro at the +3 position (48). In response to growth factor stimulation, $\mathrm{SH}-$ PTP2 associates to activated growth factor receptors through its $\mathrm{SH} 2$ domains, becomes tyrosine phosphorylated and thus leading to increased FTP activity (2,123). For full activation of the enzyme, the interaction of both $\mathrm{SH} 2$ domains with phosphoproteins is required. In contrast to what is found for SH-PTP 1, SH-PTP2 does not dephosphorylate the cytoplasmic domains of EFGR, ErbB2, PDGFRoc, PDGFRP, insulin and IGF-1 receptors (123). The main tyrosine phosphorylation site in SH-PTP2 has been mapped to $\mathrm{Tyr}^{542}$ (124). This tyrosine lies in the consensus binding motif (YTNI) for the SH2 domain of GRB2, which by association with mSOS couples Rtrk to the activation of $\mathrm{p} 21^{\mathrm{r} \ll \mathrm{M}}$. In response to PDGF stimulation, tyrosine phosphorylated SH-PTP2 acts as an adapter between PDGFR and GRB2-mSOS complex (125), suggesting that SH-PTP2 maybe an upstream component in the activation of p21"'. Indeed, restoration of the SH-PTP2 binding site in a PDGFR mutant lacking all the tyrosine autophosphorylation sites, is sufficient for full activation of p21 ${ }^{\text {ras }}$ hi response to PDGF (114), whereas expression of a dominant negative mutant of SH-PTP2 attenuates insulin-induced activation of $\mathrm{p} 21^{\text {rat }} /$ ERK pathway $(126,127)$.

\section{- $\quad$ Non-receptor tyrosine kinases}

\section{- $\quad$ Src-like tyrosine kinases}

The prototype of Src-like trk family, c-Src, is the cellular homologue of the transforming protein of Rous sarcoma virus ( $\mathrm{v}$ $\mathrm{Src})$. Members of this family of non-Rtrk include c-Src itself, c-Yes, Fyn, Lyn, and Lck. All Src-like trk contain a Gly residue at position 2 which is required for myristylation and membrane attachment. The first 70-80 amino acids of the aminoterminus are unique among the members of Src-like trk. This stretch is followed by a SH3 domain and a $\mathrm{SH} 2$ domain. The C-terminal half of the protein contains the catalytic domain and a regulatory tyrosine phosphorylation site (128).

The trk activity of c-Src is increased by dephosphorylation of the C-terminal tyrosine residue, $\mathrm{Tyr}^{527}$ (128). Mutation of this tyrosine increases trk activity and transforming potential of Src. The kinase activity of c-Src is negatively regulated by phosphorylation of $\mathrm{Tyr}^{527}$, presumably by C-terminal Src kinase (Csk) (129). The negative regulation of Src by phosphorylation involves the binding of $\mathrm{Src} \mathrm{SH} 2$ domain to the phosphorylated $\mathrm{Tyr}^{527}$, thus leading to steric hinderence of the catalytic domain (128).

The activity of Src and Src-related kinases is increased after stimulation of fibroblasts with PDGF or CSF-1, and during mitosis (130). So far, several substrates for Src have been characterized, including paxillin, focal adhesion kinase, pi 10, $\mathrm{p} ! 30, \mathrm{PI}_{3}$,-kinase, and src-associated in mitosis $68 \mathrm{kD}$ (Sam68) $(2,129)$.

\section{- Focal adhesion kinase}

Focal adhesion kinase (pp! $25^{\mathrm{FAK}}$ ) is a cytosolic trk which is predominantly localized to focal adhesions $(131,132)$. Its structure reveals a central catalytic domain flanked by large aminoand C-terminal sequences that are devoid of $\mathrm{SH} 2$ and $\mathrm{SH} 3$ domains $(131,132)$. The amino-terminal non-catalytic sequence binds to the cytosolic part of the p-integrin subunit (133). The C-terminal stretch of $\mathrm{pp} ! 25^{\mathrm{FAK}}$ contains the focal adhesion targeting sequence (FAT) which is neccessary for its localization to focal adhesions. The C-terminus also contains binding sites for two other focal adhesion-associated proteins, talin and paxillin (133).

$\mathrm{pp} ! 25^{\mathrm{FAK}}$ is tyrosine phosphorylated in response to cellular adhesion and subsequent integrin clustering and after stimulation of cells with polypeptide growth factors and mitogens (133). Tyrosine phosphorylation of tyrosine 397 of $p p ! 25^{\text {FAK }}$ facilitates the $\mathrm{SH} 2$ domain directed binding of c-Src and Fyn, resulting in activation of these enzymes (134). Activation of c-Src is implicated in the phosphorylation of other tyrosine 
residues within $\mathrm{pp} ! 25^{\mathrm{FAK}}$, thus enhancing the enzymatic activity of $\mathrm{pp} ! 25^{\mathrm{F} A \mathrm{KK}}(133)$. In addition, activation of $\mathrm{pp} ! 25^{\mathrm{FAK}}$ and c-Src induces the tyrosine phosphorylation of focal adhesion-associated proteins like paxillin, $\mathrm{p} ! 30$ and tensin (133). The tyrosine phosphorylation of these proteins is implicated in the formation of focal adhesions (133-135).

\section{INSULIN RECEPTOR SIGNALING}

\section{- The insulin receptor}

The insulin receptor is a member of Rtrk family. While most Rtrk elicit a mitogenic response, the insulin receptor also induces a metabolic response like stimulation of glucose uptake and glycogen synthesis. Upon insulin binding, the insulin receptor undergoes tyrosine phosphorylation starting at $\mathrm{Tyr}^{1138}$ and one of the two vicinal Tyr ${ }^{162}$ and Tyr $^{1163}$. The phosphorylation of the three major tyrosine autophosphorylation sites increases the phosphotransferase activity of trk. In addition to phosphorylation of the triple tyrosines in the kinase domain, minor tyrosine phosphorylation occurs at position 972 in the juxtamembrane domain, and at positions 1328 and 1344 in the C-terminal tail (136-138).

Following receptor autophosphorylation and concurrent receptor activation, several substrate proteins become tyrosine phosphorylated. These proteins include IRS-1, IRS-2 and She (52, 139,140). The tyrosine phosphorylation of these proteins contributes to the activation of postreceptor signaling pathways that lead to the various cellular responses mediated by insulin.

\section{- $\quad$ Postreceptor signaling}

Insulin receptor is among the Rtrk that stimulate the formation of p21 ras-GTP (141). This involves a GNEF that enhances the rate of guanine nucleotide binding on p21"* (70). Several studies point to an involvement of She in this process (142144). She binds directly via its PID domain to the activated insulin receptor, thus facilitating tyrosine phosphorylation of She $(50,140)$. This tyrosine phosphorylation is followed by the binding of She to GRB2/mSOS (143). The formation of a multiprotein complex between the activated insulin receptor, She, GRB2, and mSOS brings mSOS in the vicinity of membrane-bound $p 2 l^{\text {ras }}$. As a result, the exchange of GDP for GTP on $\mathrm{p} 21^{\mathrm{OT}}$ is stimulated. The activation of $\mathrm{p} 2 \mathrm{r}^{\mathrm{K}}$ is followed by activation of Raf, MEK and ERK as described earlier in this review.

Tyrosine phosphorylation of TRS- 1 and IRS-2 is an unique response of the insulin receptor family, although some members of the cytokine receptor family also induce this response (52). IRS-1 and IRS-2 are cytoplasmic proteins, which contain at least 22 potential tyrosine phosphorylation sites and two domains involved in protein-protein interactions, e.g. $\mathrm{PH}$ and PID domains $(52,139)$. The tyrosine phosphorylation of IRS-1 and presumably IRS-2 directs the binding of several SH2 domain-containing proteins, including the p85 subunit of $\mathrm{PI}_{3}$,-kinase, SH-PTP2, GRB2, and Nek (9). The binding of p85 subunit to tyrosine phosphorylated TRS-1 reflects the main step in insulin-Induced activation of $\mathrm{PI}_{3}$,-kinase (9). Regarding GRB2, several lines of evidence have indicated that $\mathrm{p} 21^{\mathrm{TM}}$ GTP formation can proceed independently of TRS-1/GRB2 complex formation (142-144).

The requirement of p21 ${ }^{\mathrm{TM}}$ and $\mathrm{PI}_{3}$, -kinase for insulin-stimulated glucose uptake and glycogen synthesis has been investigated. Activation of the p21 "'/ERK pathway alone appears not to be sufficient to stimulate glucose transport in 3T3L1 adipocytes (145). The involvement of this pathway has been subsequently exluded by expression of a dominant negative mutant of $\mathrm{p} 21^{\text {ras }}$, p2i"z,(ASNi7) $\mathrm{jhi}_{\mathrm{s}} \mathrm{p}^{2} \mathrm{i}^{\wedge}$ mutant abrogates the signaling pathway mediated by endogeneous p21"'-GTP (146), but has no effect on insulin-stimulated glucose uptake and glycogen synthesis (147). In contrast, insulin-mediated glucose uptake and glycogen synthesis is completely abolished by wortmannin, an inhibitor of $\mathrm{PI}_{3}$,-kinase $(115,147)$. This suggests that $\mathrm{PI}_{3}$,-kinase, or another wortmannin-sensitive enzyme, is an essential intermediate in insulin-induced metabolic signaling.

Insulin receptor activation also promotes the tyrosine dephosphorylation of $\mathrm{pp} ! 25^{\mathrm{FAK}}$ and paxillin $(148,149)$. The dephosphorylation of $\mathrm{pp} ! 25^{\mathrm{FAK}}$ requires phosphotyrosine residue 1158 in the activated insulin receptor and is accomplished by activation of PTP ID $(149,150)$. pp!25 $5^{\mathrm{FAK}}$ dephosphorylation by insulin is accompanied by a reduction in the amount of cytosolic stress fibres, though the physiological relevance of this event remains to be identified (150).

\section{CONCLUSIONS}

- In the last decade, considerable progress has been made towards the understanding of Rtrk signaling pathways. Ligand binding induces dimerization, activation and autophosphorylation of the Rtrk. The autophosphorylated tyrosine residues form binding sites for proteins containing SH2 or PID domains. The recruitement of these proteins to the receptor represents the first step in the activation of postreceptor signaling pathways. The specificity in signaling is probably achieved by identity of the proteins that bind to a specific Rtrk as well as tissue-specific expression of substrates.

Although a number of early postreceptor signaling pathways has been elucidated by now, their contribution to cellular responses remains to be clarified. In case of the insulin receptor, the elucidation of signaling pathways that are involved in the regulation of glucose uptake and glycogen synthesis may con- 
tribute to the identification of candidate genes involved in the pathogenesis of NIDDM.

\section{ACKNOWLEDGEMENTS}

- We acknowledge F. J. van Bussel for his help with the illustrations in this review. D.Margriet Ouwens is supported by a grant from the Netherlands Organization for the Advance of Pure Research (NWO) through the foundation of Medical Research (GB-MW).

\section{REFERENCES}

1. Ullrich A, Schlessinger J. Signal transduction by receptorswithtyrosinekinaseactivity. Cell 1990;61: 203-212

2. Van der Geer P, Hunter T, Lindberg RA. Receptor proteintyrosine kinases and their signal transduction pathways. AnnuRev Cell Biol 1994; 10: 251-337

3. Hanks SK, Quinn AM, Hunter T. The protein tyrosine kinase family: conserved features and deduced phylogeny of the catalytic domains. Science 1988; 241: 42-52

4. Hunter T. Protein kinase classification. Meth Enzymol 1991; 200: 3-37

5. Downward J, Yarden Y, Mayes E, Scarce G, Totty N, Stockwell $\mathrm{P}$ et al. Close similarity of epidermal growth , factor receptor and v-erbB oncogene protein sequences. Nature 1984; 307: 521-527

6. Ullrich A, Coussens L, Hayflick JS, Dull TJ, Gray A, Tarn AW et al. Human epidermal growth factor receptor cDNA sequence and aberrant expression of the amplified gene in A431 epidermoid carcinoma cells. Nature 1984; 309: 418-425

7. Ullrich A, Bell JR, Chen EY, Herrera R, Petruzelli LM, Dull TJ et al. Human insulin receptor and its relationship to the tyrosine kinase family of oncogenes. Nature 1985; 313: 756-761

8. Ebina Y, Ellis L, Jarnagin K, Edery M, Graf L, Clauser E et al. The human insulin receptor cDNA: the structural basis for hormone-activated transmembrane signaling. Cell 1985; 40: 747-758

9. Kahn CR. Insulin action, diabetogenes, and the cause of type II diabetes. Diabetes 1994; 43: 1066-1084

10. Taylor SI, Cama A, Accili D, Barbetti F, Quon MJ, de la Luz Sierra $\mathrm{M}$ et al. Mutations in the insulin receptor gene. EndocrRev 1992; 13: 566-595
11. Ullrich A, Gray A, Tarn AW, Yang-Fen T, Tsubokawa M, Collins C et al. Insulin-like growth factor-1 receptor primary structure: comparison with insulin receptor suggests structural determinants that define functional specificity. EMBOJ 1986; 5: 2503-2512

12. Lund PK. Insulin-like growth factor-1: Molecular biology and relevance to tissue specific expression and action. Rec Prog Harm Res 1994; 49: 49-148

13. Liu JP, Baker J, Perkins AS, Robertson EJ, Efstratiadis A. Mice carrying null mutations of the genes encoding insulin-like growth factor-1 (IGF-1) and type 1 IGF receptor (IGF- 1R). Cell 1993; 75: 59-72

14. Yarden Y, Escobedo JA, Kuang WJ, Yang-Feng TL, Daniel TO, Tremble PM et al. Structure of the receptor for platelet-derived growth factor helps define a family of closely related growth factor receptors. Nature 1986; 323:226-232

15. Jaye M, Schlessinger J, Dionne CA. Fibroblast growth factor receptor tyrosine kinases: molecular analysis and signal transduction. Biochim BiophysActa 1992; 1135:185-199

16. Fong GH, Rossant J, Gertsenstein M, BreitmanML. Role of the Flt-1 receptor tyrosine kinase in regulating the assembly of vascular endothelium. Nature 1995; 376:66-70

17. Shalaby F, Rossant J, Yamaguchi TP, Gertsenstein M, $\mathrm{Wu}$ XF, Breitman ML et al. Failure of blood island formation and vasculogenesis in Flk-1 deficient mice. $\mathrm{Na}$ ture 1995; 376: 62-66

18. Arumae U. Neurotrophins: neural antiapoptotic molecules with neurite growth-promoting properties. Biomed Rev 1995; $4: 15-27$

19. Sato TN, Tozawa Y, Deutsch U, Wolburg-Buchholz K, Fujiwara Y, Gendron-Maguire $\mathrm{M}$ et al. Distinct roles of the receptor tyrosine kinases Tie-1 and Tie-2 in blood vessel formation. Nature 1995; 376: 70-74

20. Schuchardt A, D'Agati V, Larsson-BlombergL, Constantini F, Pachis V. Defects in the kidney and enteric nervous system in mice lacking the tyrosine receptor Ret. Nature 1994; 367: 380-383

21. Lemmon MA, Schlessinger J. Regulation of signal transduction and signal diversity by receptor oligomerization. Trends Biochem Sci 1994; 19:459-463

22. Heldin $\mathrm{CH}$. Dimerization of cell surface receptors in signal transduction. Cell 1995; 80: 213-223 
23. Schlessinger J, Lax I, Lemmon M. Regulation of growth factor activation by proteoglycans: What is the role of the low-affinity receptors? Cell 1995; 83: 357-360

24. Tessier-Lavigne M. Eph receptor tyrosine kinases, axon repulsion, and the development of topographic maps. Cell 1995; 82: 345-348

25. Hanks SK. Eukaryotic protein kinase. Curr Biol 1991;!: 369-383

26. Hanks SK, Quinn AM. Protein kinase catalytic domain sequence database: identifcation and classification of family members. MethEnzymol 1991; 200: 38-62

27. Hubbard SR, Wei L, Ellis L, Hendrickson WA. Crystal structure of the tyrosine kinase domain of the human insulin receptor. Nature 1994; 372: 746-753

28. Knighton DR, Zheng J, Ten Eyck LF, Ashford VA, Xuong $\mathrm{NH}$, Taylor SS et al. Crystal structure of the catalytic subunit of cyclic adenosine monophosphate-dependent protein kinase. Science 1991; 253: 407-414

29. Pawson T, Gish GD. SH2 and SH3 domains: from structure to function. Cell 1992; 71: 359-362

30. Pawson T, Schlessinger J. SH2 and SH3 domains. Curr Biol 1993; 3: 434-442

31. Cohen GB, Ren R, Baltimore D. Modular binding domains hi signal transduction proteins. Cell 1995; 80: 237 248

32. Bork P, Margolis B. A phosphotyrosine interaction domain. Cell 1995; 80: 693-694

33. Musacchio A, Gibson T, Rice P, Thompson J, Saraste M. The PH domain: a common piece in the structural pathwork of signalling proteins. Trends Biochem Sci 1993; 18: $343-348$

34. Gibson TJ, Hyvonen M, Musacchio A, Saraste M, Birney E. PH domain: the first anniversary. Trends Biochem Sci 1994; 19: 349-353

35. Mayer BJ, Ren R, Clark KL, Baltimore D. A putative modula domain present in diverse signaling proteins. Cell 1993; 73: 629-630

36. Haslam RJ, Koide HB, Hemmings B A. Pleckstrin domain homology. Nature 1993; 363: 309-310

37. Koch CA, Anderson D, Moran MF, Ellis C, Pawson T.
SH2 and SH3 domains: elements that control interactions of cytoplasmic signaling proteins. Science 1991; 252: $668-674$

38. Mayer BJ, Jackson PK, Baltimore D. The non-catalytic src homology region 2 segment of abl tyrosine kinase binds to tyrosine phosphorylated cellular proteins with highaffinity. Proc Natl Acad Sci USA 1991; 88:627-631

39. Anderson D, Koch CA, Grey L, Ellis C, Moran MF, Pawson T. Binding of SH2 domains of phospholipase $\mathrm{C}$ gamma 1, GAP, and Src to activated growth factor receptors. Science 1990; 250: 979-982

40. Fantl WJ, Escobedo JA, Martin GA, Turck CW, del Rosario M, McCormick F et al. Distinct phosphotyrosines on a growth factor receptor bind to specific molecules that mediate different signaling pathways. Cell 1992; 69: $413-423$

41. Kuriyan J, Cowburn D. Structures of SH2 and SH3 domains. Curr Biol 1993; 3:828-837

42. Waksman G, Kominos D, Robertson SC, Pant N, Baltimore D, BirgeRB etal. Crystal structure of the phosphotyrosine recognition domain $\mathrm{SH} 2$ of $\mathrm{v}$-src complexed with tyrosine phosphorylated peptides. Nature 1992; 358: 646-653

43. Waksman G, Shoelson SE, Pant N, Cowburn D, Kuriyan J. Binding of high affinity phosphotyrosyl peptide to the Src SH2 domain: crystal structures of the complexed and peptide-free forms. Cell 1993; 72: 779-790

44. Eck MJ, Shoelson SE, Harrison SC. Recognition of a high affinity phosphotyrosyl peptide by the Src homology-2 domain of p561ck. Nature 1993; 362: 87-91

45. Booker GW, Breeze AL, Downing AK, Panayotou G, Gout I, Waterfield MD et al. Structure of an $\mathrm{SH} 2$ domain of the p85a subunit of phosphatidylinositol-3 -OH kinase. Nature 1992; 358: 684-687

46. Overduin MD, Rios CB, Mayer B J, Baltimore D, Cowburm D. 3-Dimensional solution structure of the src homology-2 domain of c-Abl. Cell 1992; 70: 697-704

47. Overduin MD, Mayer B, Rios CB, Baltimore D, Cowburn D. Secondary structure of the Src homology 2 domain of c-Abl by heteronuclear NMR spectroscopy in solution. Proc Natl Acad Sci USA 1992; 89: 11673-11677

48. SongyangZ, Shoelson SE, Chaudhuri M, Gish G, Pawson $\mathrm{T}$, Haser $\mathrm{W}$ et al. SH2 domains recognize specific phosphopeptide sequences. Cell 1993; 72: 767-778 
49. Songyang Z, Shoelson SE, McGlade J, Olivier P, Pawson T, Bustelo XR et al. Specific motifs recognized by the SH2 domains of Csk, 3BP2, fps/fes, GRB-2, HCP, SHC, Syk, and Vav. Mol Cell Biol 1994; 14: 2777-2785

50. Gustafson TA, He W, Craparo A; Schaub CD, O'Neill TJ. Phosphotyrosine-dependent interaction of She and insulin receptor substrate-1 with the NPEY motif of the insulin receptor via a novel non-SH2 domain. Mol Cell Biol 1995; 15:2500-2508

51. Kavanaugh WM, Williams LT. An alternative to SH2 domain for binding tyrosine phosphorylated proteins. Science 1994; 266: 1862-1865

52. Sun XJ, Wang LM, Zhang Y, Yenush L, Myers MG, Glasheen E et al. Role of IRS-2 in insulin and cytokine signalling. Nature 1995; 377: 173-177

53. Musacchio A, Noble M, Pauptit R, Wierenga R, Saraste M. Crystal structure of a Src-homology 3 (SH3) domain. Nature 1992; 359: 851-855

54. Noble MEM, Musacchio A, Saraste M, Courtneidge SA, Wierenga RK. Crystal structure of the SH3 domain in human fyn - comparison of the 3-dimensional structures of $\mathrm{SH} 3$ domains in tyrosine kinases and spectrin. $E M B O$ J 1993; 12: 2617-2624

55. Yu H, Rosen MK, Shin TB, Seidel-Dugan C, Brugge JS, Schreiber SL. Solution structure of the SH3 domain of Src and identification of its ligand-binding site. Science 1992; 258: 1665-1668

56. Booker GW, Gout I, Downing AK, Driscoll PC, Boyd J, Waterfield MD et al. Solution structure and ligand-binding site of the SH3 domain of the p85-alpha subunit of phosphatidylinositol 3-kinase. Cell 1993; 73: 813-822

57. Kohda D, Hatanaka H, Odaka M, Mandiyan V, Ullrich A, Schlessinger J et al. Solution structure of the $\mathrm{SH} 3$ domain of phospholipase C-gamma. Cell 1993; 72: 953960

58. Ren R, Mayer BJ, Cicchetti P, Baltimore D. Identification of a ten-amino acid proline-rich $\mathrm{SH} 3$ binding site. Science 1993; 259: 1157-1161

59. Yu H, Chen JK, Feng S, Dalgarno DC, Brauer AW, Schreiber SL. Structural basis for the binding of prolinerich peptides to SH3 domains. Cell 1994; 76: 933-945

60. Inglese J, Koch WJ, Touhara K, Lefkowitz RJ. G|3Y interactions with PH domains and ftos-MAPK signaling pathways. Trends Biochem Sci 1995; 20: 151-156

61. Ferguson KM, Lemmon MA, Schlessinger J, Sigler PB.

- Crystal structure at 2.2 A resolution of the pleckstrin homology domain from human dynamin. Cell 1994; 79: 199-209

62. Harlan JE, Hajduk PJ, Yoon HS, Fesik SW. Pleckstrin homology domains bind to phosphatidylinositol-4,5bisphosphate. Nature 1994; 371: 168-170

63. Songyang Z, Cantley LC. Recognition and specificity in protein tyrosine kinase-mediated signalling. Trends Biochem Sci 1995; 20: 470-475

64. Lowy DR, Willumsen BM. Function and regulation of ras. Aпnи Rev Biochem 1993; 62: 851-893

65. Bourne HR, Sanders DA, McCormick F. The GTPase superfamily: conserved structure and molecular mechanism. Nature 1991; 349: 117-127

66. Hall A. The cellular function of small GTP binding proteins. Science 1990; 249: 635-640

67. Bos JL. Ras oncogenes in human cancer: a review. Cancer Res 1989; 49:4682-4689

68. Bollag G, McCormick F. Regulators and effectors of ras proteins. Annu Rev Cell Biol 1991; 7: 601-632

69. Buday L, Downward J. Epidermal growth factor regulates the exchange rate of guanine nucleotides on $\mathrm{p} 21^{\mathrm{nM}}$ in fibroblasts. Mol Cell Biol 1993; 13: 1903-1910

70. Medema RH, de Vries-Smits AMM, van der Zon GCM, Maassen JA, Bos JL. Ras activation by insulin and epidermal growth factor through enhanced exchange of guanine nucleotides on $\mathrm{p} 21^{\mathrm{rar}}$. Mol Cell Biol 1993; 13: 155162

71. Bowtell D, Fu P, Simon M, Senior P. Identification of murine homologues of the Drosophila Son of sevenless gene: potential activators of ras. ProcNatlAcad. Sci USA 1992; 89: 6511-6515

72. Lowenstein EJ, Daly RJ, Batzer AG, Li W, Margolis B, Lammers $\mathrm{R}$ et al. The $\mathrm{SH} 2$ and $\mathrm{SH} 3$ domain-containing proteins GRB2 links receptor tyrosine kinases to ras signalling. Cell 1992; 70: 431-442

73. Clark SG, Stern MJ, Horvitz HR. C. elegans cell signaling gene sem-5 encodes a protein with $\mathrm{SH} 2$ and $\mathrm{SH} 3$ domains. Nature 1992; 356: 340-344 
74. Olivier JP, Raabe T, Henkemeyer M, Dickson B, Mbamalu G, Margolis B etal. A Drosophila SH2-SH3 adaptor protein implicated in coupling the sevenless tyrosine kinase to an activator of ras guanine nucleotide exchange, Sos. Cell 1993; 73: 179-191

75. Simon MA, Dodson GS, Rubin GM. An SH3-SH2-SH3 protein is required for $\mathrm{p} 21$ "'" activation and binds to sevenless and Sos proteins in vitro. Cell 1993; 73: 169177

76. Gale NW, Kaplan S, Lowenstein EJ, Schlessinger J, BarSagi D. Grb2 mediates the EGF-dependent activation of guanine nucleotide exchange on Ras. Nature 1993; 363: 88-92

77. Skolnik EY, Batzer A, Li N, Lee CH, Lowenstein E, Mohammadi $\mathrm{M}$ et al. The function of Grb2 in linking the insulin receptor to ras signaling pathways. Science 1993; 260: 1953-1955

78. Buday L, Downward J. Epidermal growth factor regulates $p 2 l^{\text {ras }}$ through the formation of a complex of receptor, grb2 adapter protein, and SOS nucleotide exchange factor. Cell 1993; 73: 611-620

79. Chardin P, Camonis JH, Gale NW, Van Aelst L, Schlessinger J, Wigler MH et al. Human Sos 1: a guanine nucleotide exchange factor for Ras that binds to grb2. Science 1993; 260: 1338-1343

80. Egan SE, Giddings BW, Brooks MW, Buday L, Sizeland AM, Weinberg RA. Association of Sos Ras exchange protein with Grb2 is implicated in tyrosine kinase signal transduction and transformation. Nature 1993; 363:45-51

81. Li N, Batzer A, Daly R, Yajnik V, Skolnik E, Chardin P et al. Guanine nucleotide-releasing factor hSOSl binds to Grb2 and links receptor tyrosine kinases to Ras signalling. Nature 1993; 363: 85-88

82. Rozakis-Adcock M, Fernely R, Wade J, Pawson T, Bowtell D. The SH2 and SH3 domains of mammalian Grb2 couple the EGF receptor to the Ras activator mSOS 1. Nature 1993; 363: 83-85

83. Pellici G, Lanfrancone L, Grignani F, McGlade J, Cavallo F, Forni G et al. A novel transforming protein (She) with an SH2 domain is implicated in mitogenic signal transduction. Cell 1992; 70: 93-104

84. Rozakis-Adcock M, McGlade J, Mbamalu G, Pellici G, Daly R, Schlessinger J et al. Association of the She and Grb2/Sem-5 SH2-containing proteins is implicated in ac- tivation of the Ras pathway by tyrosine kinases. Nature 1992; 360: 689-692

85. Boguski MS, McCormick F. Proteins regulating Ras and its relatives. Nature 1993; 366: 643-654

86. Davis RJ. The mitogen-activated protein kinase signal transduction pathway. JBiolChem 1993; 268: 14553-14556

87. Vojtek AB, Hollenberg SM, Cooper JA. Mammalian Ras interacts directly with the serine/threonine kinase Raf. Cell 1993; 74: 205-214

88. Zhang XF, Settleman J, Kyriakis JM, Takeuchi-Suzuki E, Elledge SJ, Marshall MS et al. Normal and oncogenic p21 TM proteins bind to the amino-terminal regulatory domain of c-Raf-1. Nature 1993; 364: 308-313

89. Wame PH, Rodriguez-Viciana P, Downward J. Direct interaction of Ras and the amino-terminal region of raf1 in vitro. Nature $1993 ; 364: 352-355$

90. McCormick F. Raf: the holy grail of Ras biology ? Trends Cell Biol 1994; 4: 347-350

91. Leevers SJ, Paterson HF, Marshall CJ. Requirement for Ras in Raf activation is overcome by targeting Raf to the plasma membrane. Nature 1994; 369: 411-414

92. Stokoe D, MacDonald SG, Cadwallader K, Symons M, Hancock JF. Activation of Raf as a result of recruitment to the plasma membrane. Science 1994; 264: 1463-1467

93. Kyriakis JM, App H, Zhang XF, Banerjee P, Brautigan DL, Rapp UR et al. Raf-1 activates MAP kinase kinase. Nature 1992; 358: 417-421

94. Alessi DR, Saito Y, Campbell DG, Cohen P, Sithanandam G, Rapp U et al. Identification of the sites in MAP kinase kinase-1 phosphorylatedby p74raf-1. EMBOJ1994; 13: 1610-1619

95. Zheng CF, Guan KL. Activation of MEK family kinases requires phosphorylation of two conserved Ser/Thr residues. EMBOJ 1994; 13: 1123-1131

96. Marshall CJ. Specificity of receptor tyrosine kinase signaling: transient versus sustained extracellular signal-related kinase activation. Cell 1995; 80: 179-185

97. Waters SB, Holt KH, Ross SE, Syu LJ, Guan KL, Saltiel AR et al. Desensitization of Ras activation by a feed back dissociation of the Sos/Grb2 complex. JBiol Chem 1995; 270: 20883-20886 
98. Davis RJ. MAPKs: new INK expands the group. Trends Biochem Sci 1994; 19: 470-473

99. Coso OA, Chiariello M, Yu JC, Teramoto H, Crespo P, $\mathrm{Xu} \mathrm{N}$ et al. The small GTP-binding prteins Racl and cdc42 regulate the activity of the JNK/SAPK signaling pathway. Cell 1995; 81: 1137-1146

100. Minden A, Lin A, Claret FX, Abo A, Karin M. Selective activation of the JNK signaling cascade and c-jun transcriptional activity by the small GTPases Rac and Cdc42Hs. Cell 1995; 81: 1147-1157

101. Gibbs JB, Schaber MD, Allard WJ, Sigal IS, Scolnick EM. Purification of ras GTPase activating protein from bovine brain. Proc Natl Acad Sci USA 1988; 85: 50265030

102. Trahey M, McCormick F. A cytoplasmic protein stimulates normal N-ras p21 GTPase but does not affect oncogenic mutants. Science 1987; 238: 542-545

103. Downward J, Graves JD, Warne PH, Rayter S, Cantrell DA. Stimulation of $\mathrm{p} 21^{\text {raj }}$ upon T-cell activation. Nature 1990; 346: 719-723

104. Ellis C, Moran M, McCormick F, Pawson T. Phosphorylation of GAP and GAP-associated proteins by transforming and mitogenic tyrosine kinases. Nature 1990; 343: 377-381

105. Martin GA, Yatani A, Clark R, Conroy L, Polakis P, Brown AM et al. GAP domains responsible for ras $\mathrm{p} 21-$ dependent inhibition of muscarinic atrial $\mathrm{K}^{+}$channel currents. Science 1992; 255: 192-194

106. Medema RH, de Laat WL, Martin GA, McCormick F, Bos JL. GTPase activing protein SH2-SH3 domains induce gene expression in a Ras dependent fashion. Mol Cell Biol 1992; 12: 3425-3430

107. Wong G, Muller O, Clark R, Conroy L, Moran MF, Polakis $\mathrm{P}$ et al. Molecular cloning and nucleic acid binding of the GAP-associated tyrosine phosphoprotein p62. Cell 1992; 69: 551-558

108. Settleman J, Narasimhan V, Foster LC, Weinberg RA. Molecular cloning of cDNAs encoding GAP-associated protein pi90: implications for a signaling pathway from Ras to the nucleus. Cell 1992; 69: 539-549

109. Settleman J, Albright CF, Foster LC, Weinberg RA. Association between GTPase activators for Rho and Ras families. Nature 1992; 359: 153-154
110. McGlade J, Brunkhorst B, Anderson D, Mbamalu G, 1 Settlleman J, Dedhar S ei al. The N-terminal region of GAP regulates cytoskeletal structure and cell adhesion. EMBOJ 1993; 12: 3073-3081

111. Dhand R, Hiles I, Panayotou G, Roche S, Fry MJ, Gout I ei al. PI 3-kinase is a dual-specificity enzyme: autoregulation by an intrinsic protein-serine kinase activity. $E M B O$ J1994; 13: 522-533

112. Hunter T. When is a lipid kinase not a lipid kinase ? When it is a protein kinase. Cell 1995; 83: 1-4

113. Fry MJ, Waterfield MD. Structure and function of phosphatidylinositol 3-kinase: a potential second messenger system involved in growth control. Phil Trans $R$ Soc LondB 1993; 340: 337-344

114. Valius M, Kazlauskas A. Phospholipase C-gamma 1 and phosphatidylinositol 3 kinase are the downstream mediators of the PDGF receptor's mitogenic. Cell 1993; 74: 321-334

115. CheathamB, Vlahos CJ, CheathamL, WangL, Blenis J, Kahn CR. Phosphatidylinositol 3-kinase is required for insulin stimulation of pp70 S6 kinase, DNA synthesis and glucose transporter translocation. MolCellBiol 1994; 14: 4902-4911

116. BosJL. A target for phosphoinositide 3-kinase: Akt/PKB. Trends Biochem Sci 1995; 20: 441-442

117. Chung J, Grammar TC, Lemon KP, Kazlauskas A, Blenis J. PDGF-dependent regulation of pp70-S6 kinase is coupled to receptor-dependent binding and activation of phosphatidylinositol 3-kinase. Nature 1994; 370: 71-75

118. Downward J. Regulating S6 kinase. Nature 1994; 371: 378-379

119. Bar Sagi D, Rotin D, Batzer A, Mandiyan V, Schlessinger J. SH3 domains direct cellular localization of signaling molecules. Cell 1993; 74: 83-91

120. Hunter T. Protein tyrosine phosphatases: the other side of the coin. Ce// 1989; 58: 1013-101

121. Mourey RJ, Dixon JE. Protein tyrosine phosphatases: characterization of extracellular and intracellular domains. Curr Opin Genet Dev 1994; 4: 31-39

122. Shen SH, BastienL, PosnerBI, ChretienP. A protein tyrosine phospahatase with sequence similarity to the $\mathrm{SH} 2$ domain of the protein tyrosine kinases. Nature 1991; 352: 736-739 
123. Vogel W, Lammers R, Huang J, Ullrich A. Activation of a phosphotyrosine phosphatase by tyrosine phosphorylation. Science 1993; 259: 1611-1614

124. Bennet AM, Tang TL, Sugimoto S, Walsh CT, Neel BG. Protein tyrosine phosphatase SHPTP2 couples platelet derived growth factor beta to Ras. Proc NatlAcad Sci USA 1994; 91: 7335-7339

125. Li W, Nishimura R, Kashishian A, Batzer AG, Kirn WJ, Cooper JA et al. A new function for a phosphotyrosine phosphatase: linking Grb2-Sos to a receptor tyrosine kinase. Uol Cell Biol 1994; 14: 509-517

126. Noguchi T, Matozaki T, Horita K, Fujijoka Y, Kasuga M. Role of SH-PTP2, a protein tyrosine phosphatase with Src homology 2 domains in insulin-stimulated Ras activation. Mol Cell Biol 1994; 14: 6674-6682

127. Yamauchi K, Milarski KL, Saltiel AR, Pessin J. Protein tyrosine phosphaste SH-PTP2 is a required positive effector of insulin downstream signaling. Proc NatlAcad Sci USA 1995; 92: 664-668

128. Cantley LC, Auger KR, Carpenter C, Duckworth B, Graziani A, Kapeller R et al. Oncogenes and signal transduction. Cell 1991; 64: 281-302

129. Courtneidge SA, Fumagalli S. A mitotic function for Src? Trends Cell Biol 1994; 4: 345-347

130. Shenoy S, Chachalaparampil I, Bagrodia S, Lin PH, Shalloway D. Role of p34cdc2-mediatedphosphorylations in two step activation of pp60-c-src during mitosis. Proc NatlAcadSci USA 1992; 89: 7237-7241

131. Hanks SK, Calalb MB, Harper MC, Patel SK. Focal adhesion protein tyrosine kinase phosphorylated in response to cell spreading on fibronectin. Proc NatlAcadSci USA 1992; 89: 8487-8489

132. Schaller MD, Borgman CA, Cobb BS, Vines RR, Reynolds AB, Parsons JT. pp!25 ${ }^{\mathrm{FAK}}$, a structurally unique protein kinase associated with focal adhesions. Proc Natl AcadSci USA 1992; 89:5192-5196

133. Schwartz MA, Schaller MD, Ginsberg MH. Integrins: emerging paradigms of signal transduction. Annu Rev Cell Biol 1995; 11: 549-599

134. Clark EA, Brugge JS. Integrins and signal transduction pathways: the road taken. Science 1995; 268: 223-229

135. JokuschBM,BubeckP, GiehlK,KroemkerM,Moschner
J, Rothkegel M et al. The molecular architecture of focal adhesions. Annu Rev Cell Biol 1995; 11: 379-416

136. White MF, Shoelson SE, Keutmann H, Kahn CR. A cascade of tyrosine phosphorylation in thebeta-subunit activates the phosphotransferase of the insulin receptor. BiolChem 1988; 263: 2969-2980

137. Tornqvist HE, Pierce MW, Frackelton HR, Nemenoff RA, Avruch J. Identification of the insulin receptor tyrosine residues autophosphorylated in vitro. JBiol Chem 1987; 262: 10212-10219

138. Tornqvist HE, Gunsalus JR, Nemenoff RA, Frackelton RA, Pierce MW, Avruch J. Identifcation of the insulin receptor tyrosine residues undergoing insulin-stimulated phosphorylation in intact rat hepatoma cell. JBiol Chem 1988; 263: 350-359

139. Sun XJ, Rothenberg P, Kahn CR, Backer JM, Araki E Wilden PA et al. Structure of the insulin receptor substrate (IRS-1) defines an unique signal transduction protein. Nature 1991; 352: 73-77

140. Pronk GJ, McGlade J, Pelicci G, Pawson T, Bos JL. Insulin-induced phosphorylation of the 46 and $52 \mathrm{kD}$ She proteins. JBiol Chem 1993; 268: 5748-5753

141. Burgering BMT, Medema RH. Maassen JA, van de Wetering ML, van der EB AJ, McCormick F et al. Insulin stimulation of gene expression mediated by p21"' activation. EMBOJ 1991; 10: 1103-1109

142. Ouwens DM, van derZon GCM, Pronk GJ, Bos JL, Moller $\mathrm{W}$, Cheatham B et al. A mutant insulin receptor induces formation of a Shc-Grb2 complex and p21 ${ }^{\text {ral }}$-GTP without detectable interaction of insulin receptor substrate1(IRS-1) with Grb2: evidence for IRS-1-independent

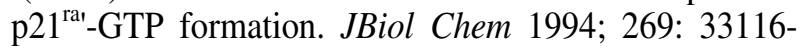
33122

143. Pronk GJ, de Vries-Smits AMM, Buday L, Downward J, Maassen JA, Medema RH et al. Involvement of She in insulin- and epidermal growth factor-induced activation ofp21 $1^{\mathrm{TM}}$ Mol Cell Biol 1994; 14: 1575-1581

144. Sasaoka T, Draznin B, Leitner JW, Langlois WJ, Olefsky JM. She is the predominant signaling molecule coupling insulin receptors to activation of guanine nucleotide releasing factor and $\mathrm{p} 21^{\mathrm{m}} \mathrm{GTP}$ formation. J Biol Chem 1994; 269: 10734-10738

145. Van den Berghe N, Ouwens DM, Maassen JA, van Mackelenbergh MGH, Sips HCM, Krans HMJ. Activa- 
tion of the /te/mitogen activated protein kinase signaling pathway alone is not sufficient to induce glucose uptake in 3T3L1 adipocytes, Mol CellBiol 1994; 14: 2372-

2377

146. De Vries-Smits AMM, Burgering BMT, Leevers SJ, Marshall CJ, Bos JL. Involvement of p21"' in activation of extracellular signal regulated kinase 2. Nature 1992; 357: 602-605

147. Dorrestijn J, Ouwens DM, van den Berghe N, Bos JL, Maassen JA. Expression of a dominant-negative Ras mutant does not affect stimulation of glucose uptake and glycogen synthesis by insulin. Diabetologia 1996; 39: In press

148. Pillay TS, Sasaoka T, Olefsky JM. Insulin stimulates the tyrosine dephosphorylation of pp!25 Focal Adhesion Kinase. JBiol Chem 1995; 270: 991-994

149. Ouwens DM, Mikkers HMM, van der Zon GCM, SteinGerlach M, Ullrich A, Maassen JA. Insulin-induced tyrosine dephosphorylation of focal adhesion kinase and paxillin requires active phosphotyrosine phosphatase ID. Submitted for publication

150. Ouwens DM, van der Zon GCM, Maassen JA. Unpublished observation

Received 20 March 1996

Accepted 15 May 1996

Address for correspondence:

Dr J. Antonie Maassen

Sylvius Laboratory

Department of Medical Biochemistry

Medical Faculty

State University Leiden

Wassenaarseweg 72

NL-2333 AL Leiden

The Netherlands

Tel: 31 (71) 5276127

Fax: 31 (71) 5276125 